دراسات في آثار الوطن العربيه 1

\title{
النيل والمصريون
}

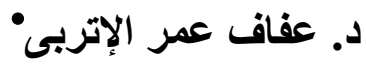

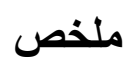

قال تعالى " وجعلنا من الماء كل شئ حى" صدق الله العظيم.

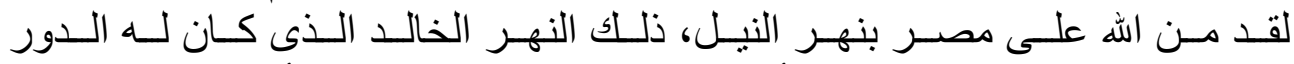

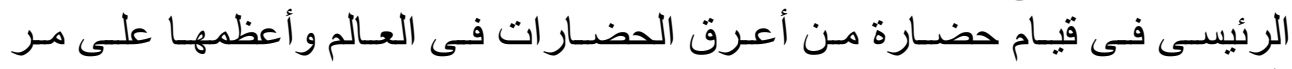

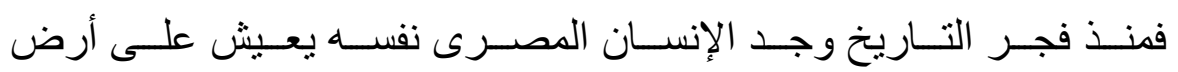

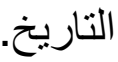

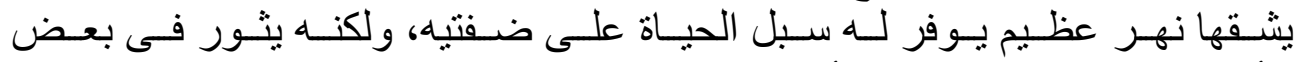

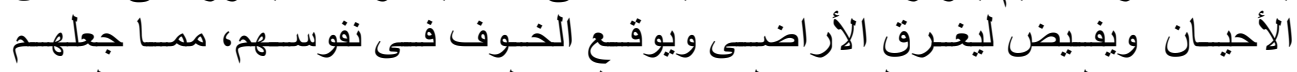

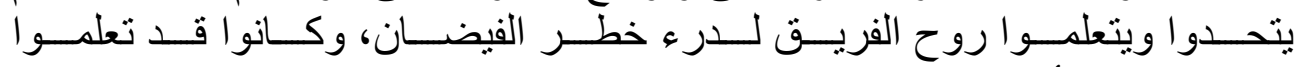

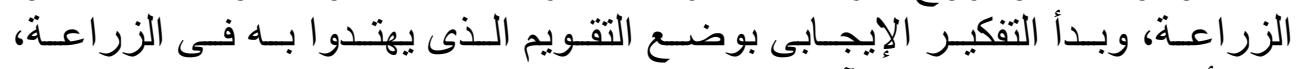
وهو أكثر التقاويم دقة حتى الآن.

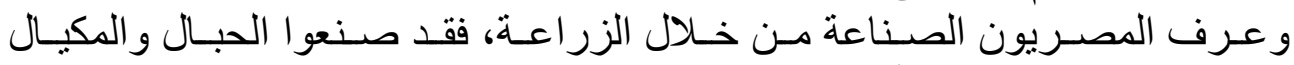

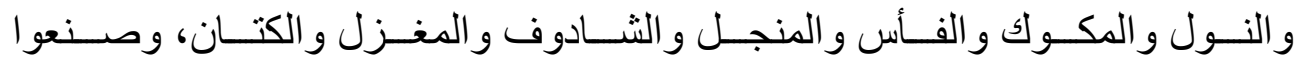

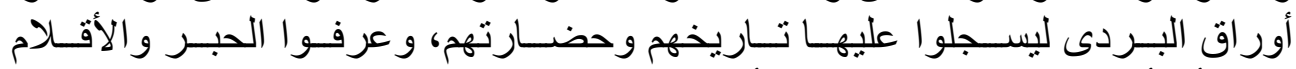

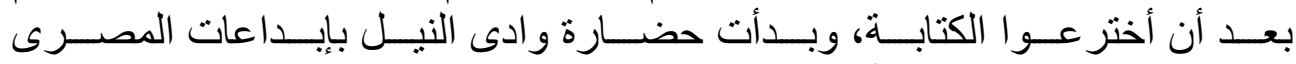

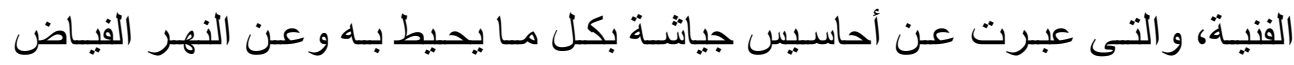

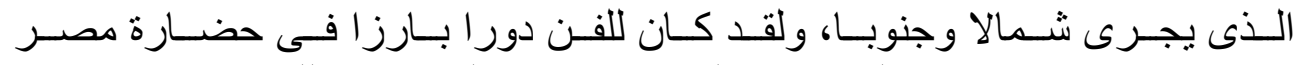

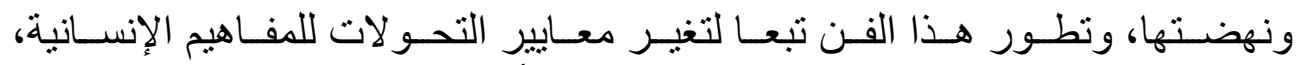

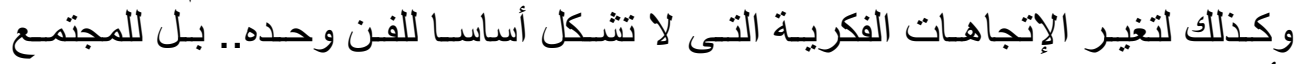

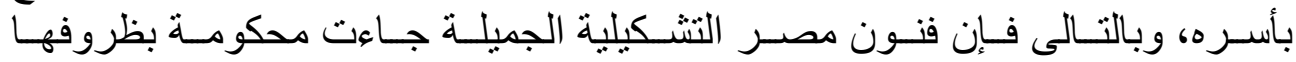

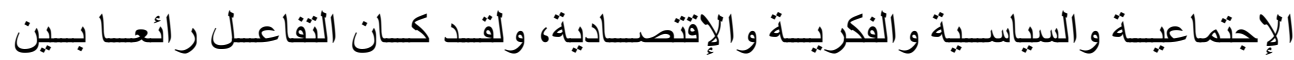
المصرى وبيئته التى حباه الله بها من طبيعة فريدة الإنهاء

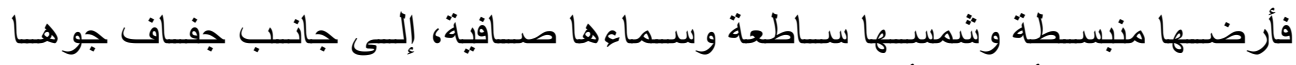

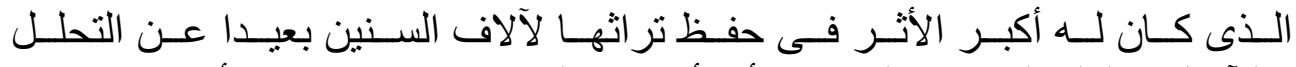

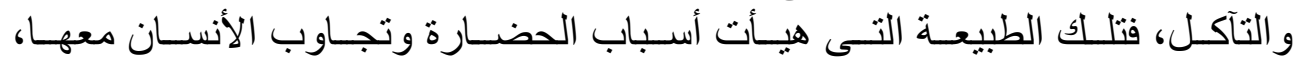

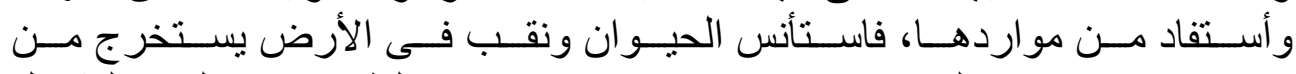

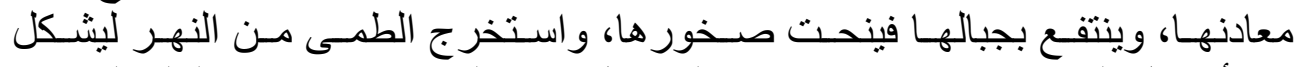

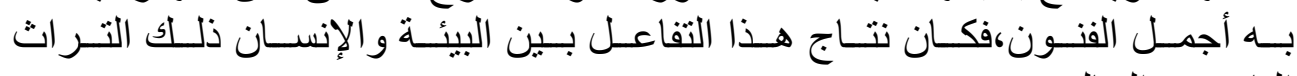

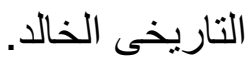

• مديرعام ترميم آثار المتاحف (الأسبق) - المجلس الأعلى للآثار - مصر 


\section{دراسات في آثار الوطن العربيه}

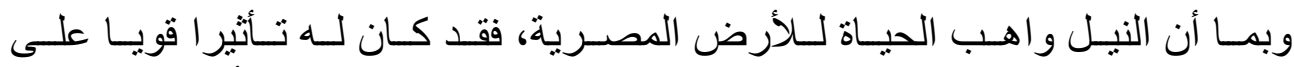

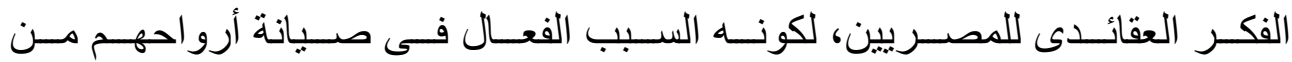

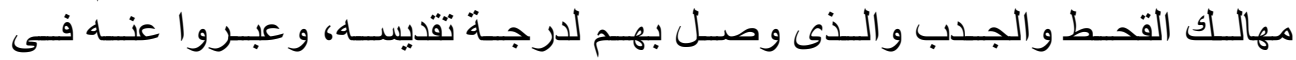

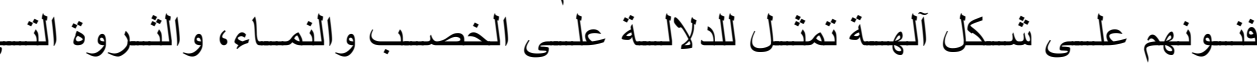

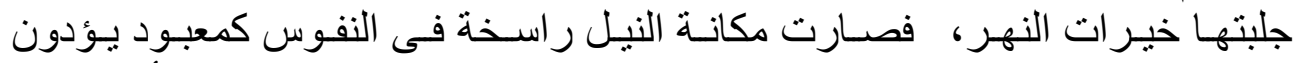

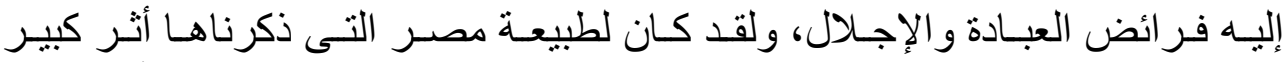

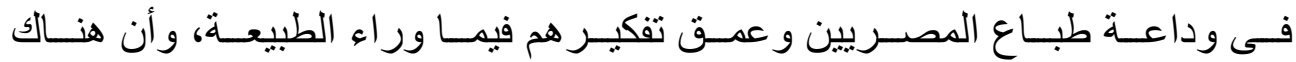

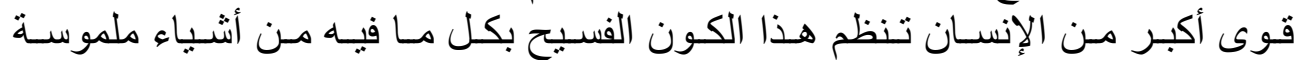

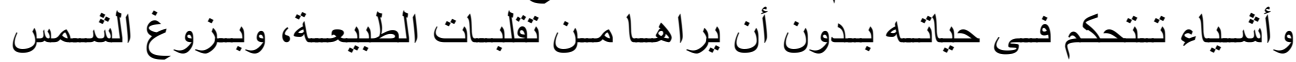

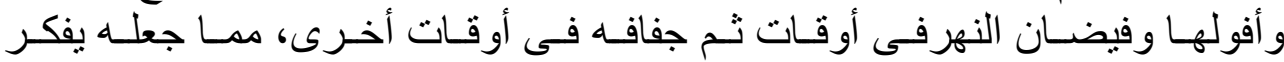

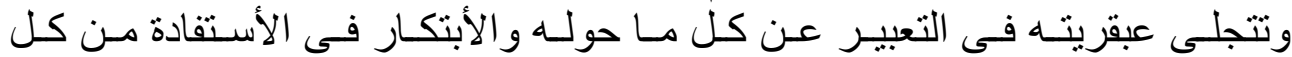

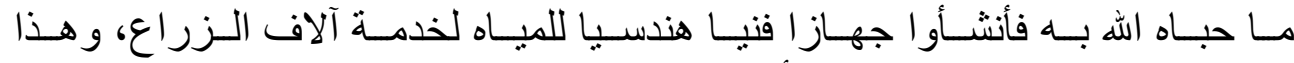

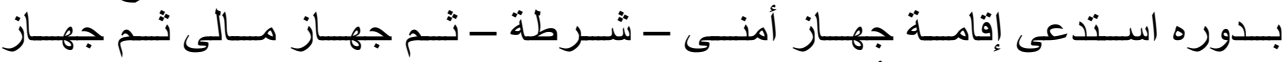

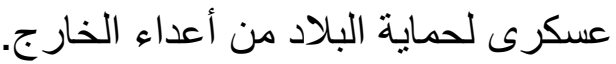

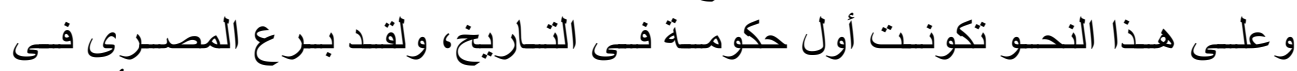

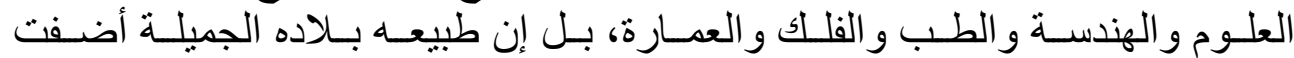

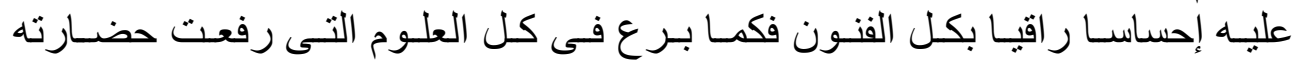

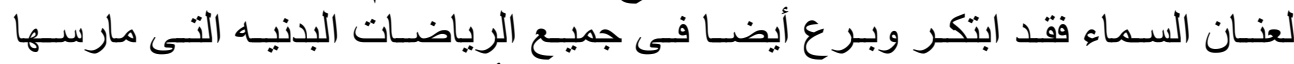

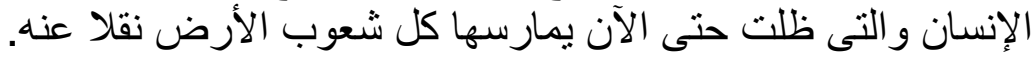

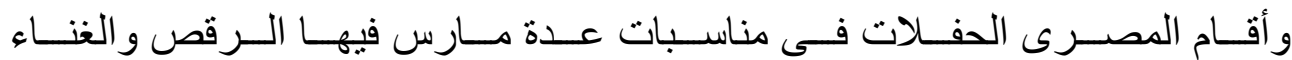

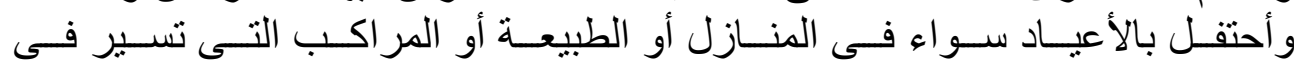

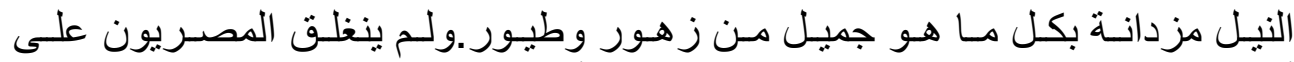
أنفسهم بل تبادلوا التجارة مع كثير من هن البلدان الأخرى.

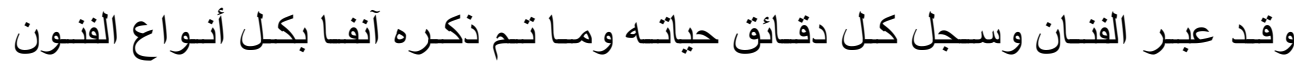

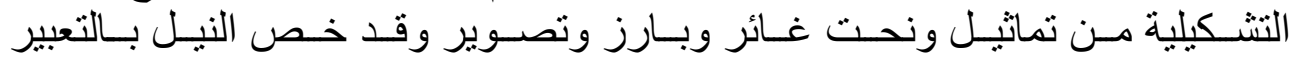

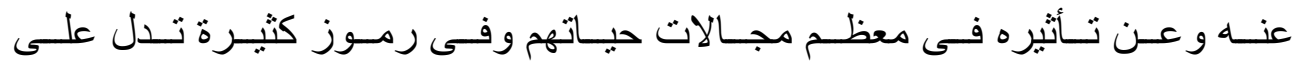
مكانته السامية عندهم، وترك تك المصرى لنا فنونا لم ترق إليها حضارة أخرى.

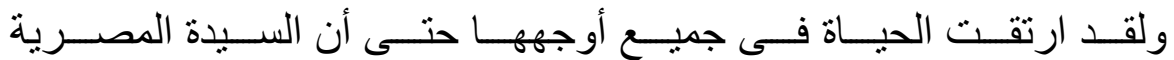

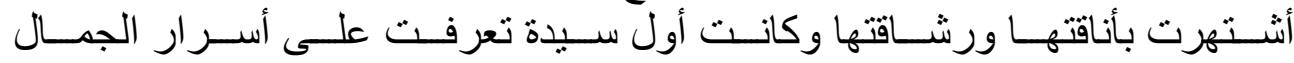

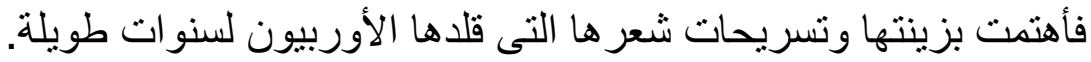

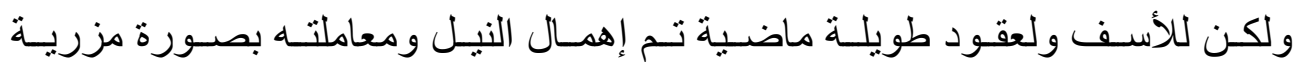

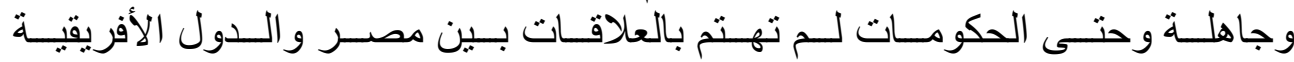

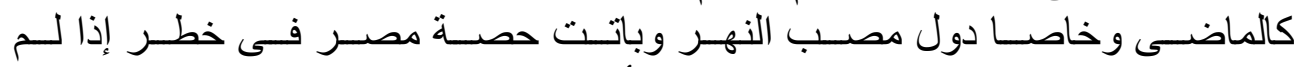

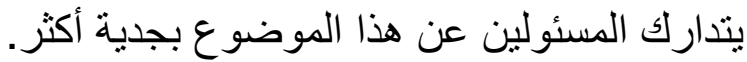




\section{دراسات في آثار الوطن العربيه}

\section{The Nile and the Egyptians}

God says in the Holy Quran: "and (We) made from water every living thing" (The Prophets: 30 ).

God granted Egypt with the River Nile, that eternal river that played the main role in raising the greatest and most majestic civilization in history.

Since the dawn of history, the Egyptians found themselves living on a land penetrated by a great river that provided them with the ways of life on its banks. The River revolted sometimes and floods to drawn the lands and causing fear to their souls, a matter that made them challenge and acquire the team spirit to ward off the dangers of the flood. It made them learn agriculture and think positively by putting a very punctual calendar to help them in agriculture. A calendar that is considered the most accurate to the time being.

The Egyptians knew industry through agriculture, the manufactured ropes, bushels, looms, shuttles, axes, sickles, sweeps, spindles and flax. They manufactured papyrus to document their history and civilization; they knew ink and pencils after inventing writing. The civilization of the Nile Valley started with the artistic creations of the Egyptian that represented his high sensitivity towards the surrounding and the River that runs north and south. Art played an important role in the Egyptian civilization and it developed to cope with the change in the human standards. It also changed to adapt the changes in the ways of thinking that not only form a basis for art alone but to the whole society as well. Therefore, the Egyptian fine art was influenced by the social, political, intellectual and economical circumstances. The interaction between the Egyptian and his God given nature was great.

Egypt possessed a plain land, shining sun, clear sky besides a dry weather that played a main role in preserving its heritage for thousands of years from disintegration and decay. This nature paved the way for this great civilization and the Egyptians used its resources; he domesticated animals, explored the land in search of minerals, cut the rocks from its mountains and extracted clay from the river to form the most beautiful artifacts. The outcome of this interaction between man and nature was this immortal cultural heritage. 
Since the Nile has given life to the land of Egypt, it had a great influence on the Egyptians' ideological thought because it was the only means to save their lives from the perils of drought and famine to an extent that made them sanctify it. The Nile was represented in art in the form of fertility, growth, and wealth god.

The status of the Nile became stable in the souls of the Egyptians as a worshipped god. The nature of Egypt which we previously mentioned created the calm temper of the Egyptians and deepened their metaphysical thought. They knew that there is a power greater than man that organizes this huge universe with its physical objects and other elements that control man's life without being seen like the vagaries of nature, sunrise, and eclipse, the flood during particular times and drought during others. Matters that urged him to think, and his genius to manifest in expressing his surroundings and innovation of new methods to use all the God given bounties. He established a architectural and technical apparatus for water to help peasants then a security apparatus (police) then a financial apparatus and a military one to help the country from foreign enemies.

In this way, the first government in history is formed. The Egyptian mastered science, architecture, medicine and astronomy, the beautiful nature of its country gave him an elevated sense in all types of art. He mastered all types of science that raised his civilization to the sky; he also created and developed many sports that are being practiced till today by many people around the globe.

The Egyptian celebrated many occasions and expressed his celebration through dancing and singing in his house, in nature or on boats floating in the Nile and decorated with flowers and birds.

The Egyptian artist represented and documented the details of his life through all types of art like sculpturing, drawing and carving specifying the Nile with many symbols that represent its great status to the Egyptians leaving us masterpieces that no other civilization possessed. 


\section{النيل والمصريون}

قال تعالى " وجعلنا من الماء كل شئ حى " صدق الله العظيم.

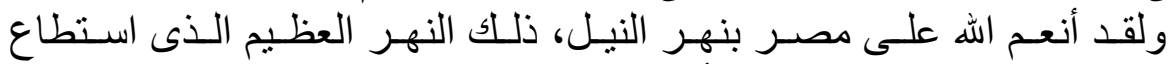

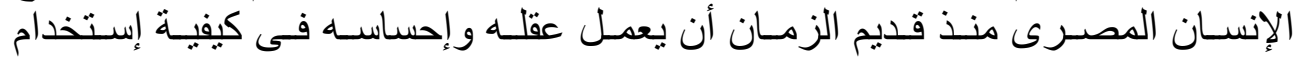

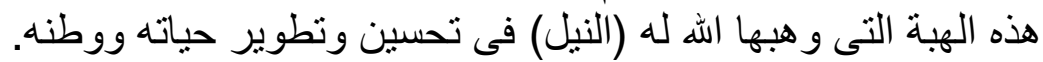

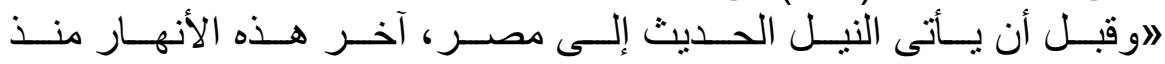

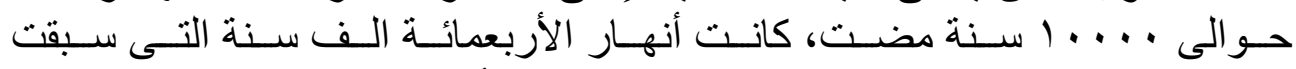

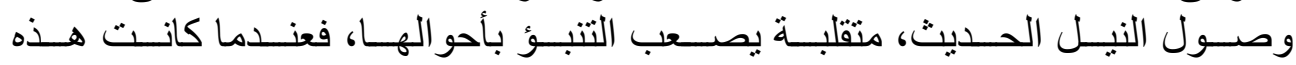

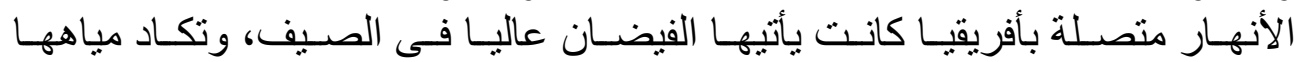

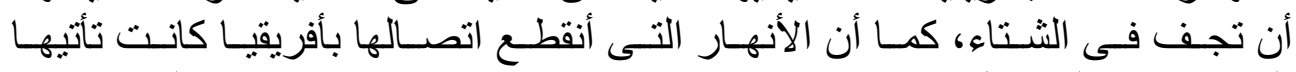

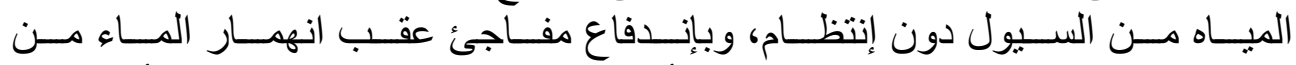

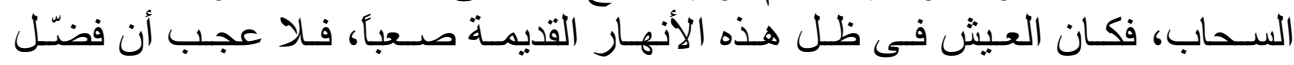

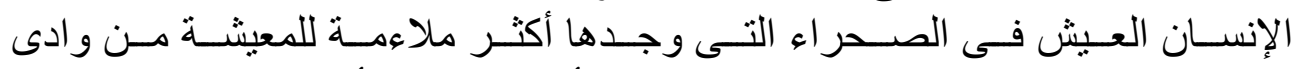

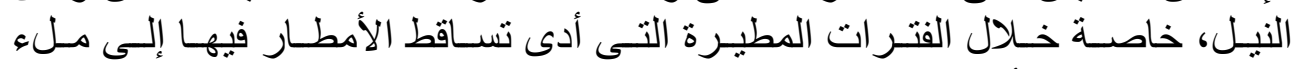

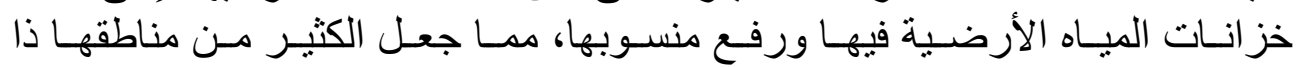

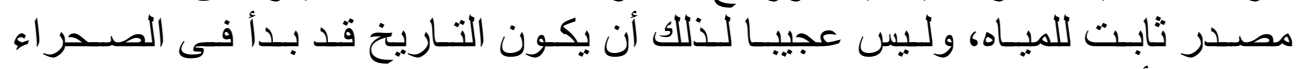

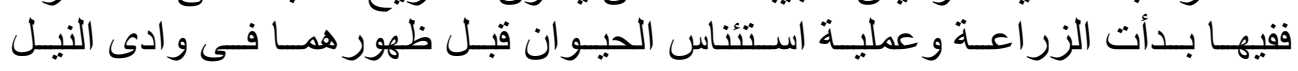
بعدة آلاف من السنين.

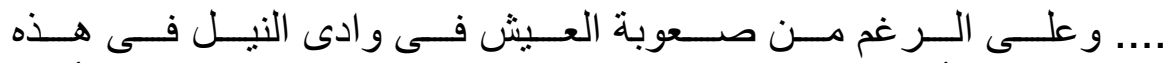

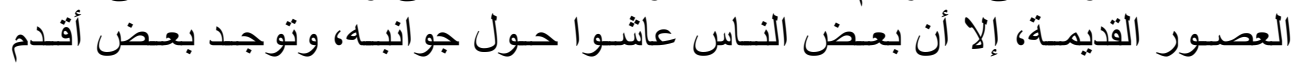

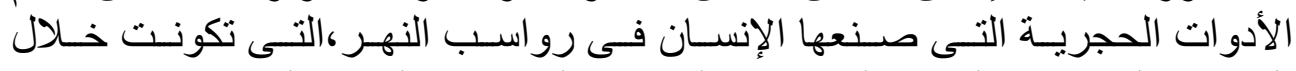

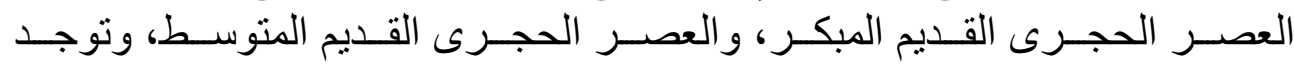

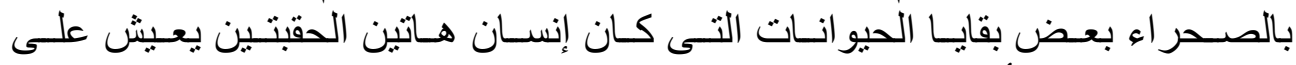

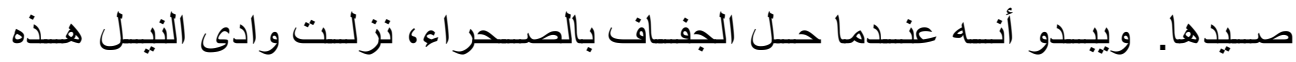

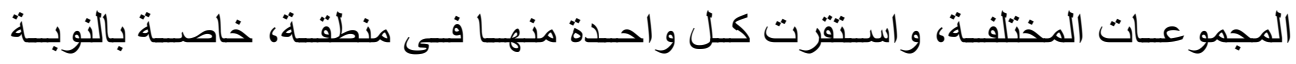

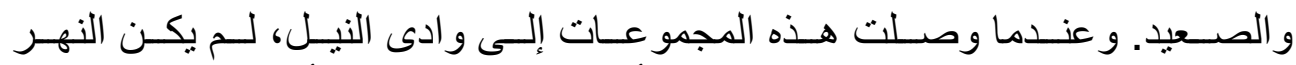

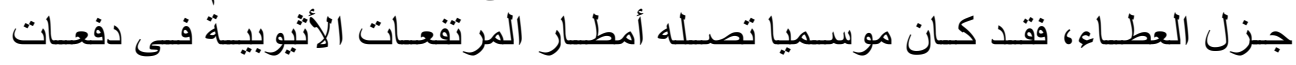

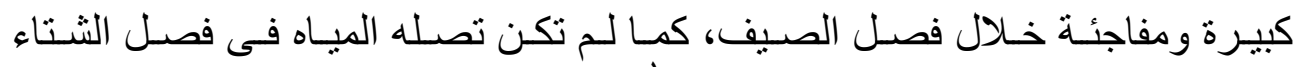
فينكمش وقتها إلى برك صغيرة ومل ومتناثرةه '.

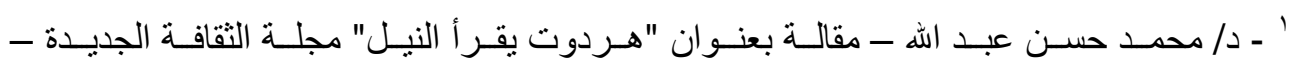

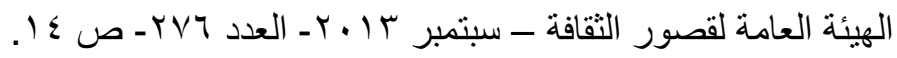


دراسات في آثار الوطن العربيه 10

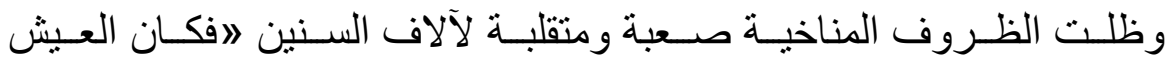

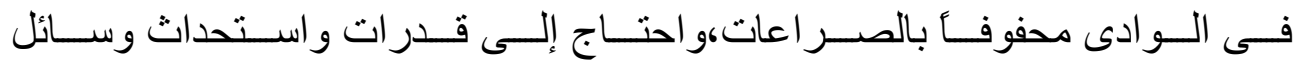

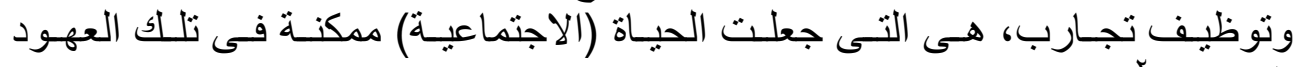

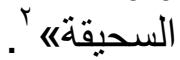

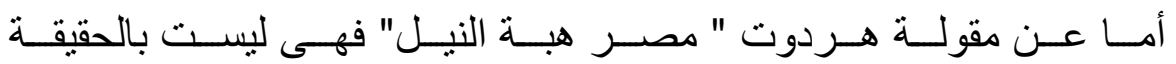

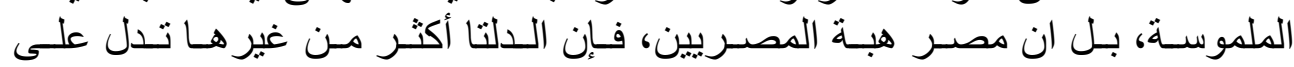

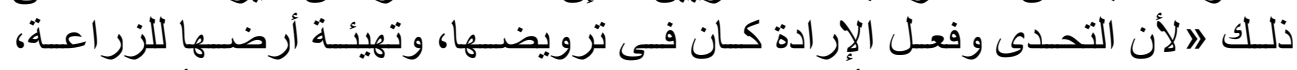

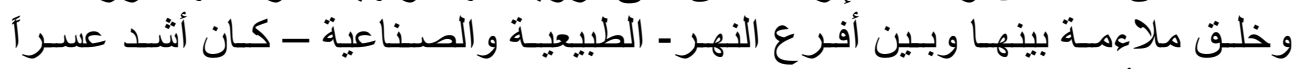

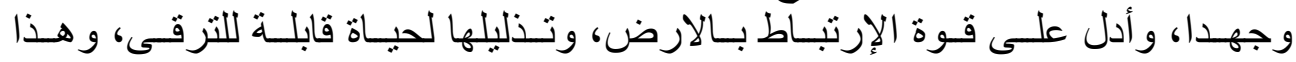

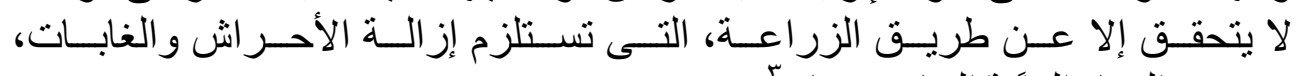

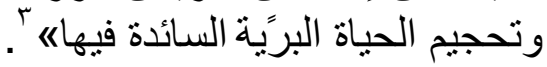

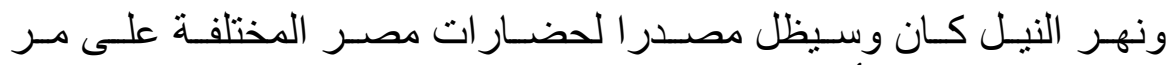

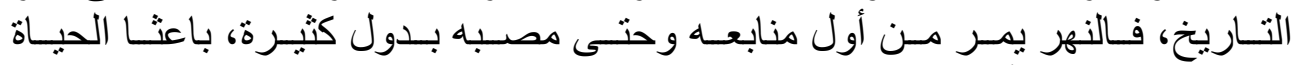

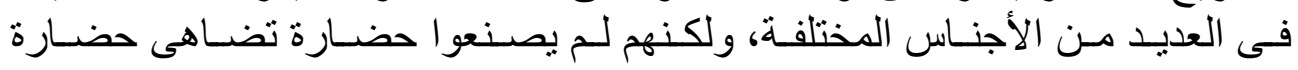

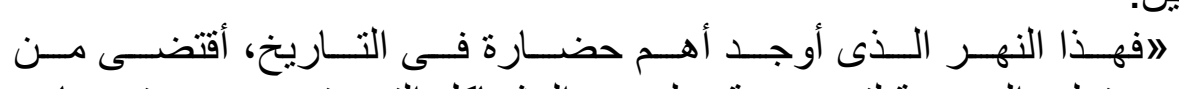

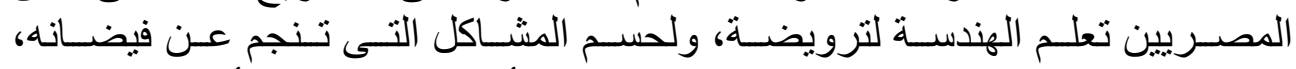

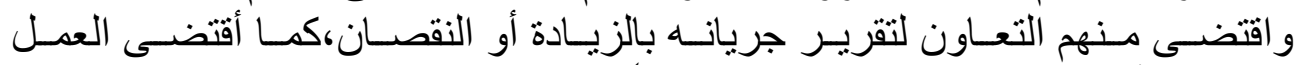

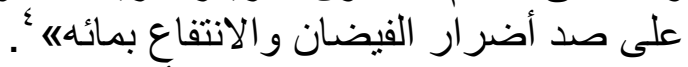

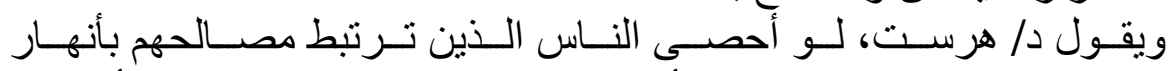

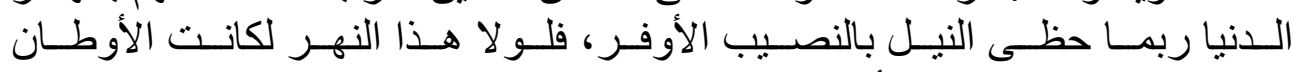

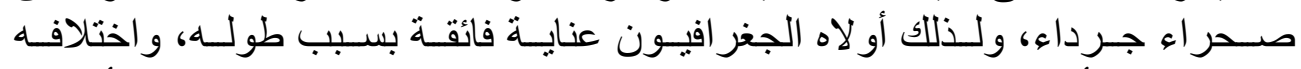

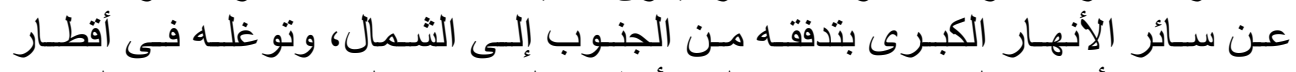

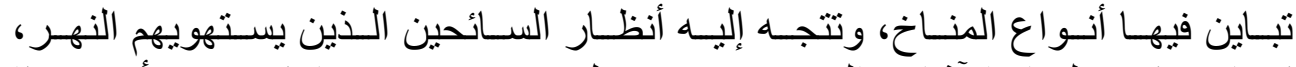

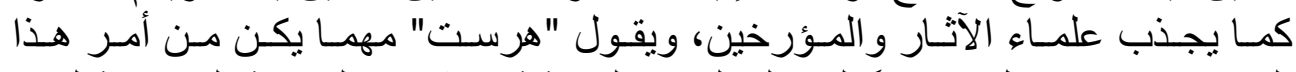

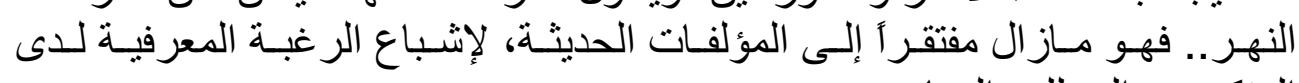
المفكرين و المحللين السياسيين.

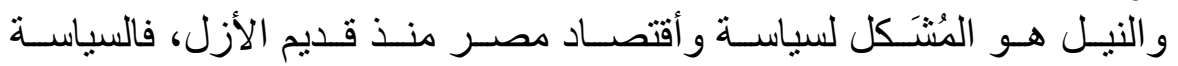

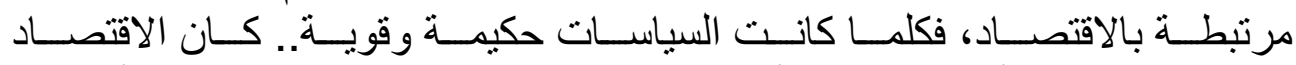

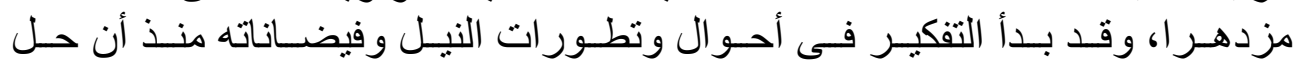

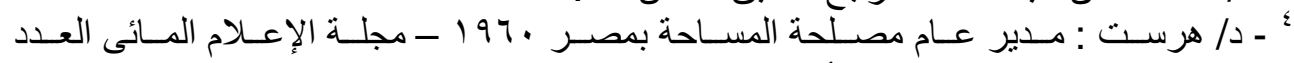
السابع و العشرون ه9 99 (، وزارة الأشغال والموارد المائية (بتلخيص). 


\section{دراسات في آثار الوطن العربيه 1}

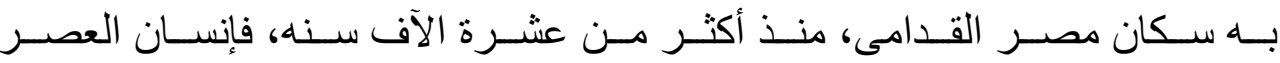

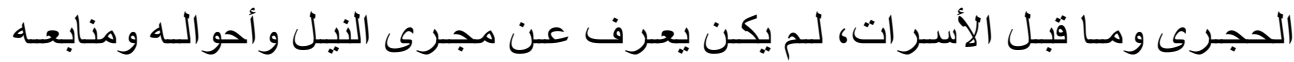

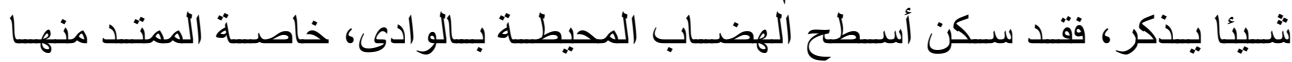

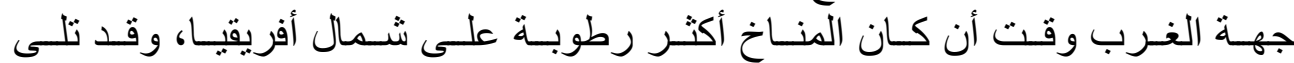

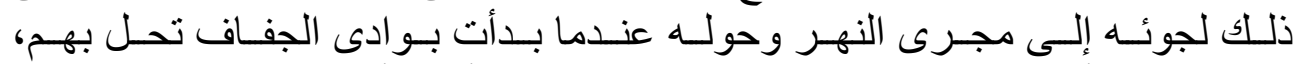

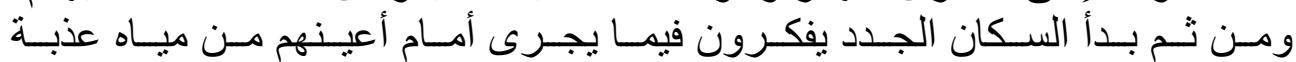

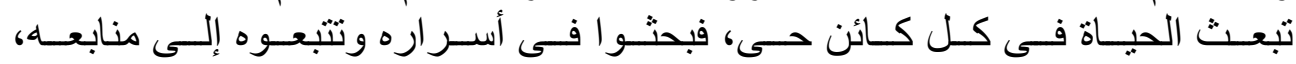

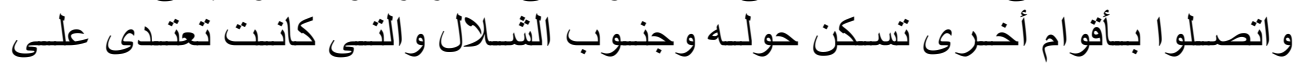

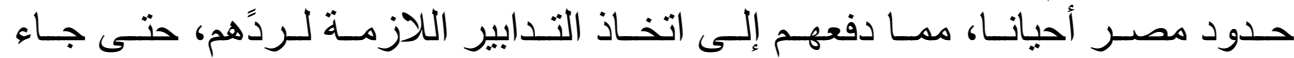

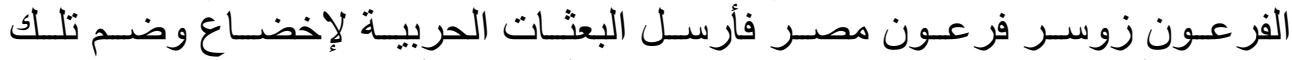

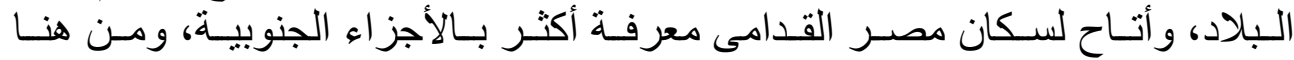

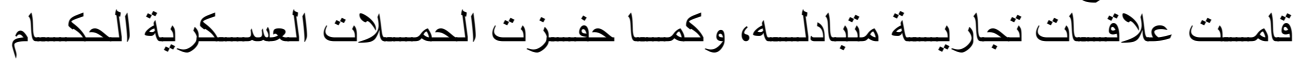

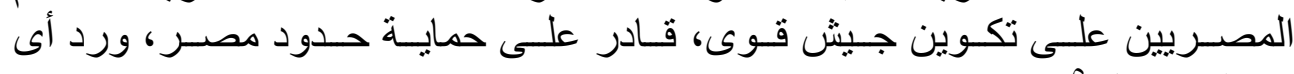
عدوان عنهاهُ

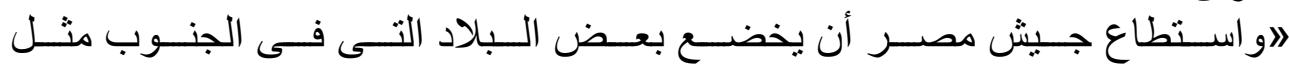

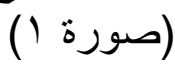

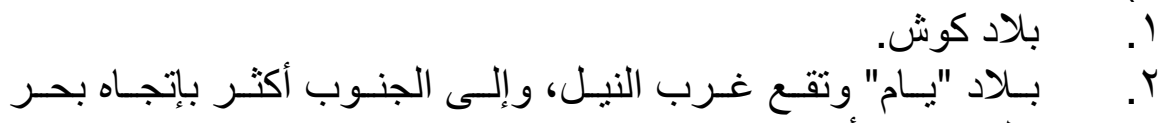

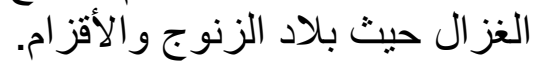

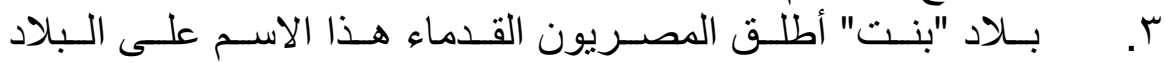

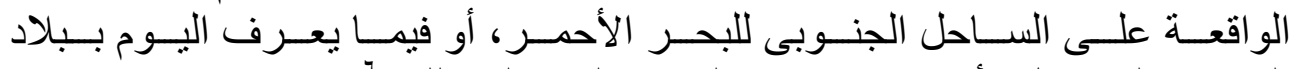

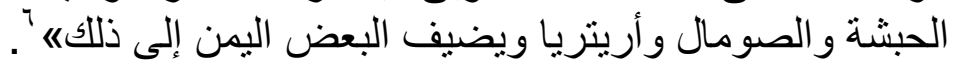

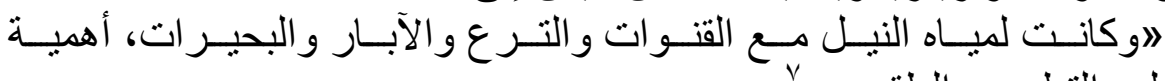

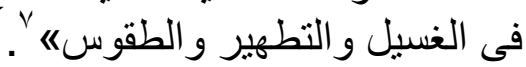

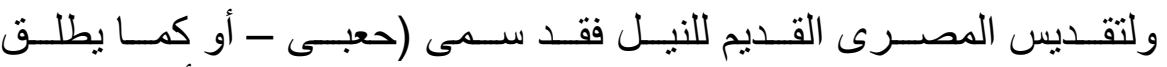

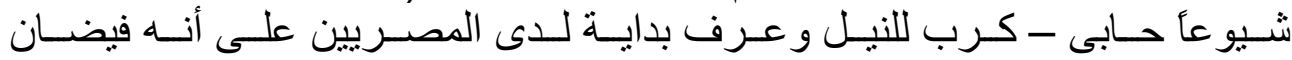

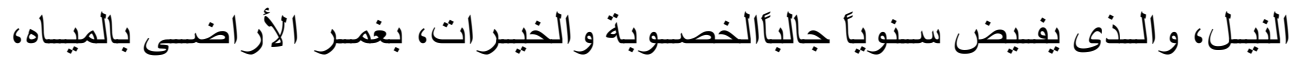

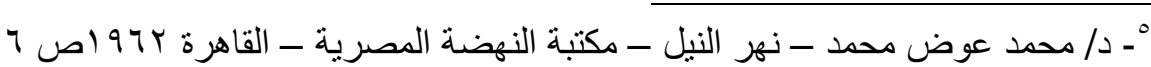

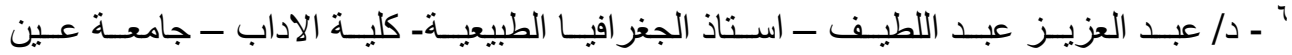
شمس -كتاب جغرافية وادى النيل ( بتلخيص) - دار الحرية للطباعة.

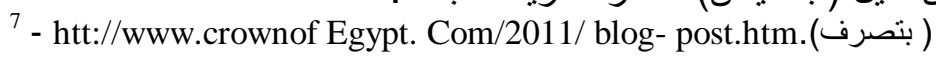




\section{دراسات في آثار الوطن العربيه 1}

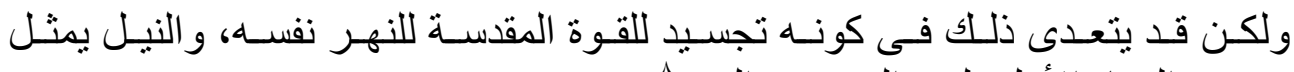

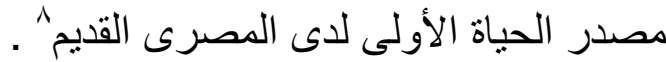

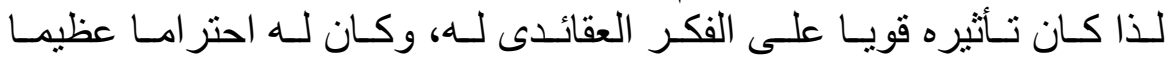

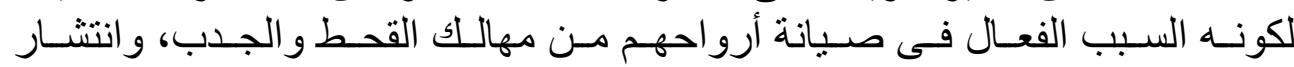

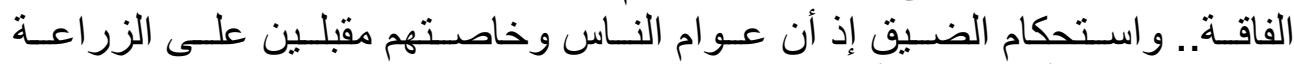

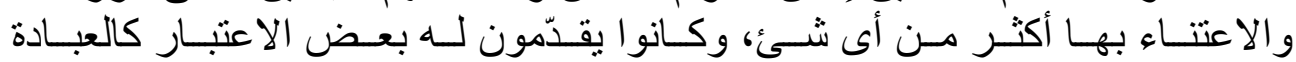

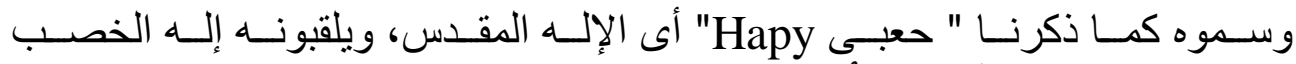

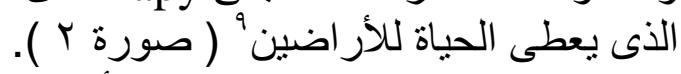

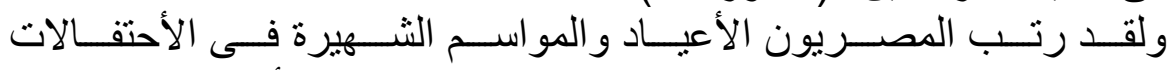

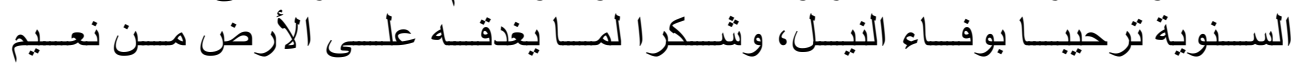

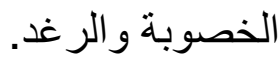

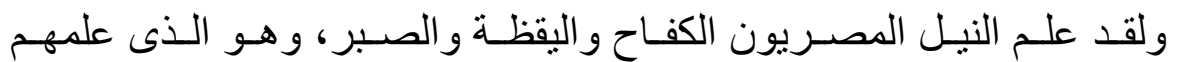

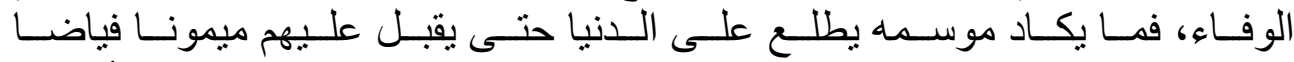

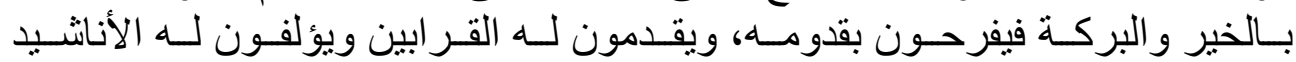

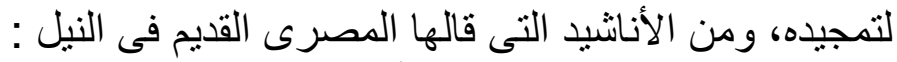

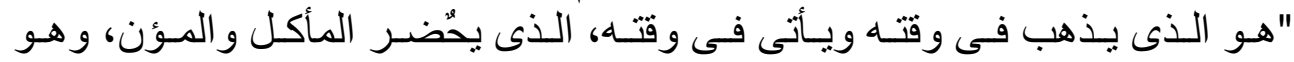

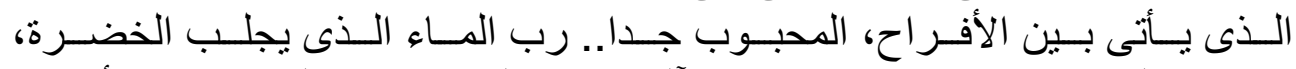

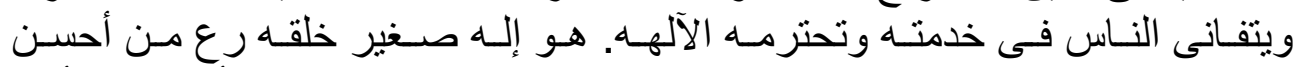

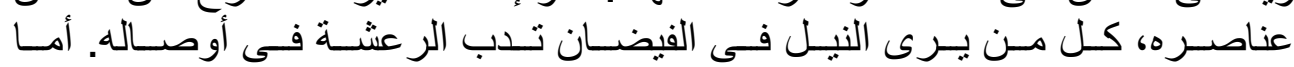

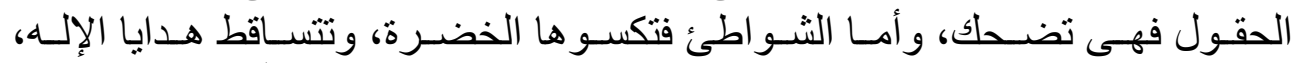

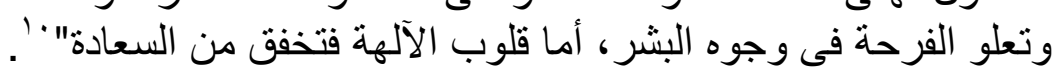

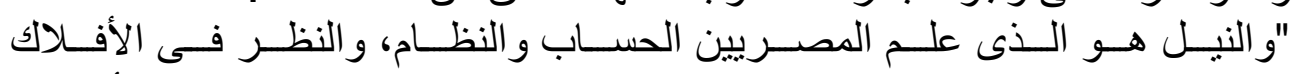

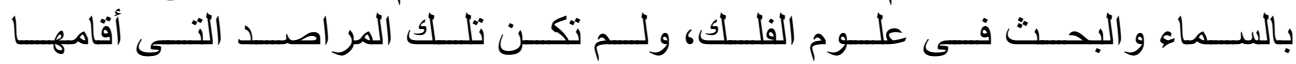

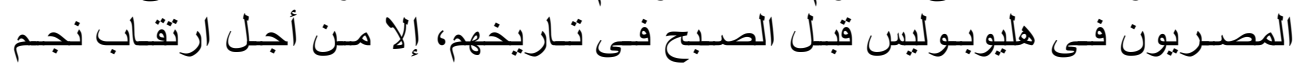

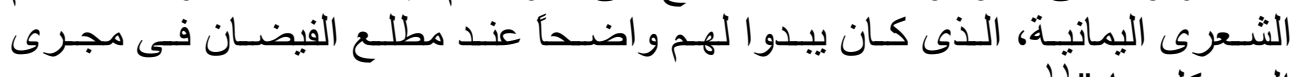

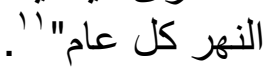

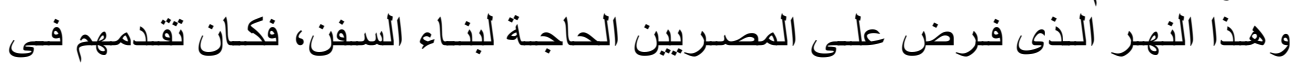

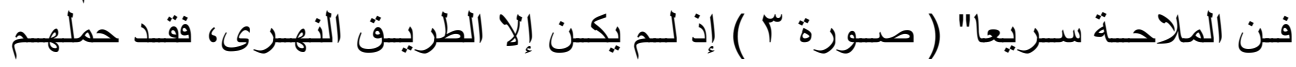

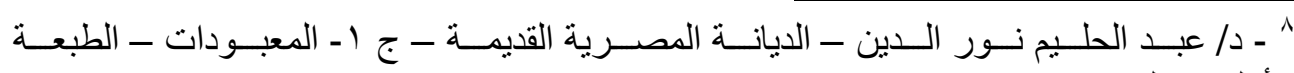

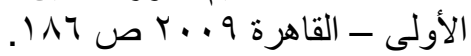

9 - Maspero. G the Daen of Civilization. London. S.P.C.K.1897- p 37.

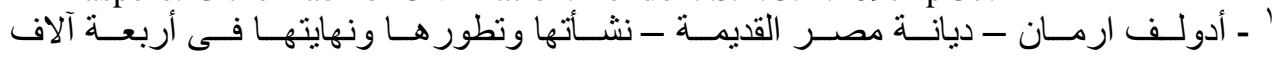

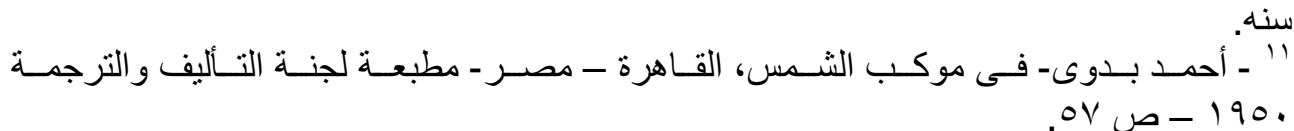




\section{دراسات في آثار الوطن العربيه 1}

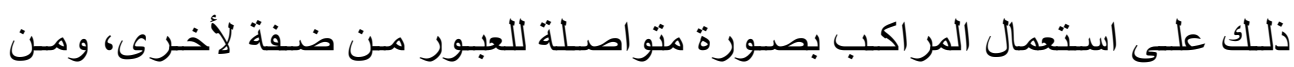

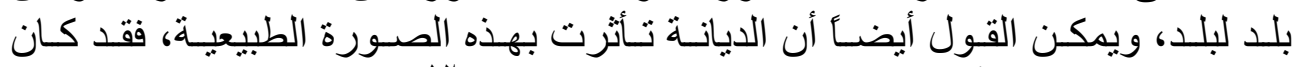

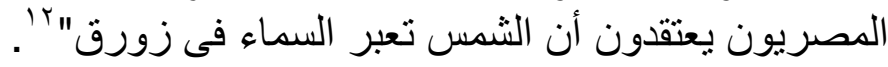

ذلك أنهـا تشـرق كل صـباح لتوجـد الحيـاة "وتسـير فـى زورق لتنيـر عـالم الأحيـاء

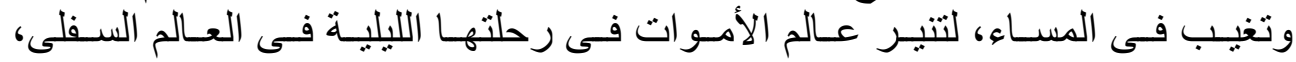

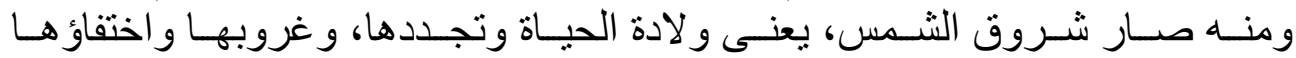

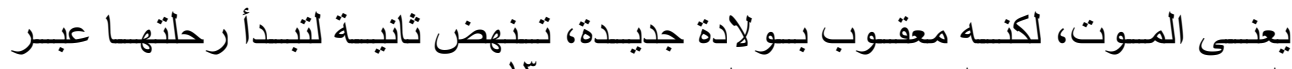

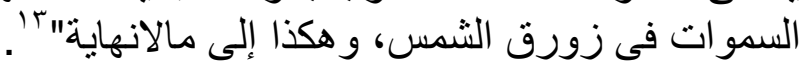

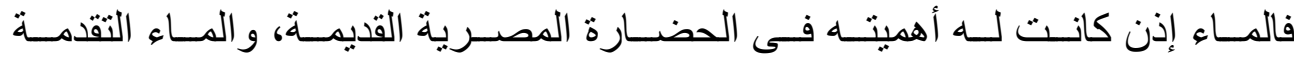

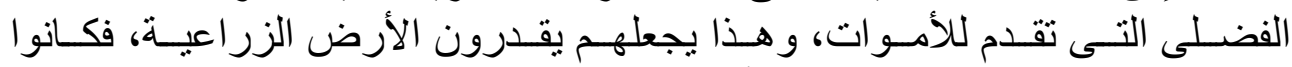

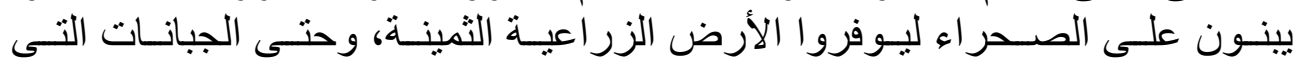

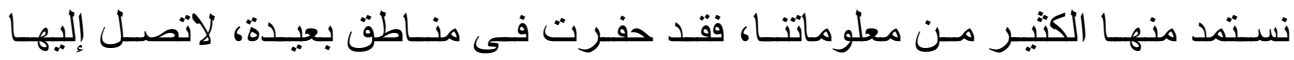
الرطوبة التى تتسرب فى التربة على جانبى النهر تسربا عميقا.

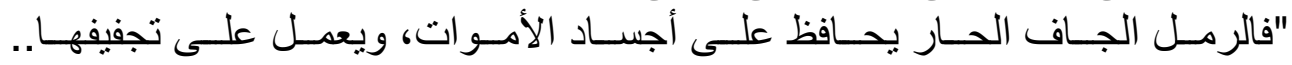

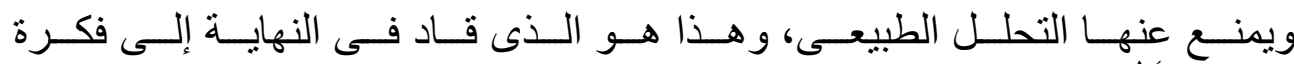
التحنيط" و

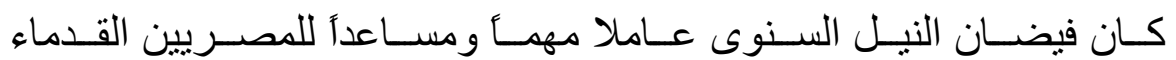

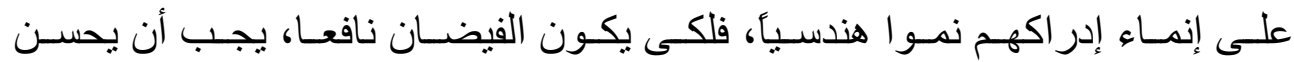

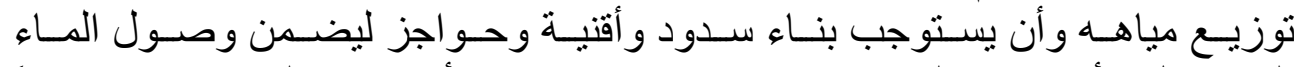

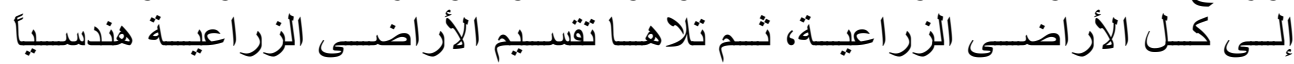

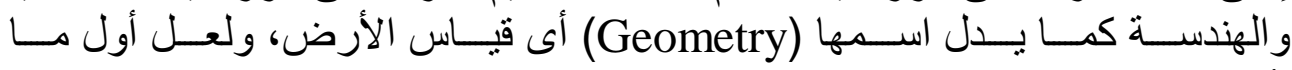

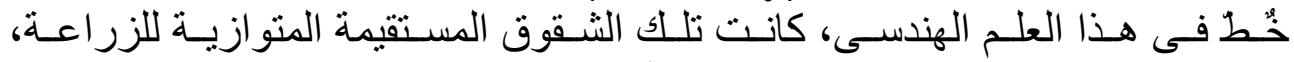

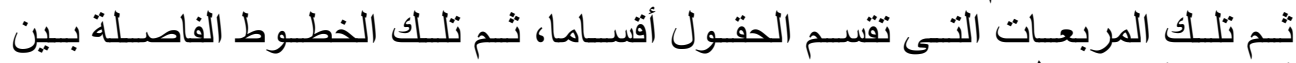

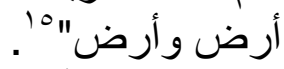

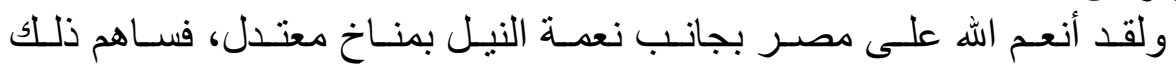

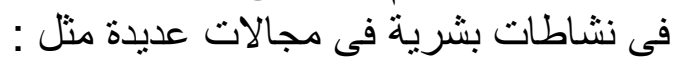

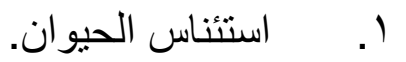

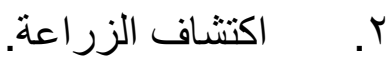

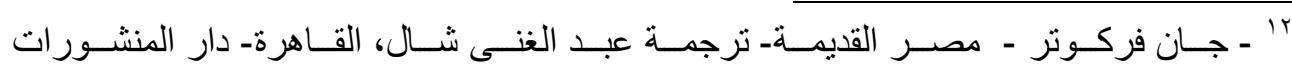

13 - Macquitty,Wiliam. Abu Simbel. Newyork. Gp.Putuam's. sons, 1956, p18.

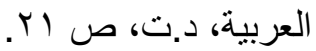

${ }^{14}$ - Wiliam.Op.Cit. p18 - Macquitty.

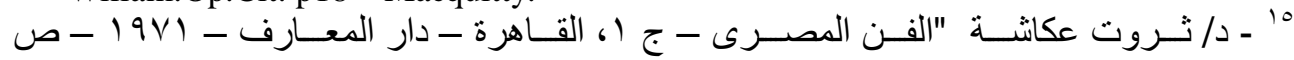




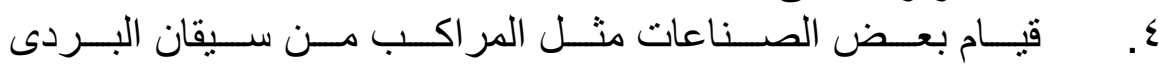

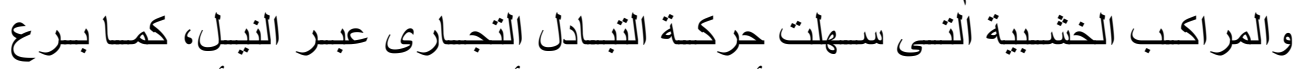

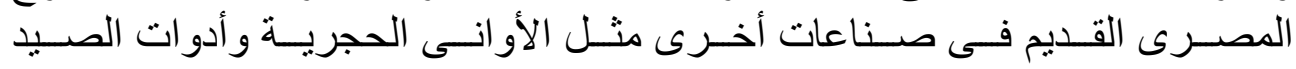

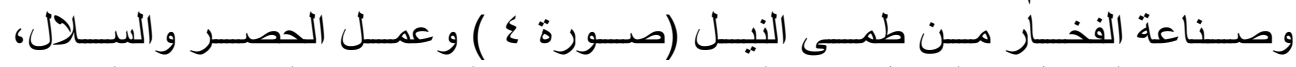

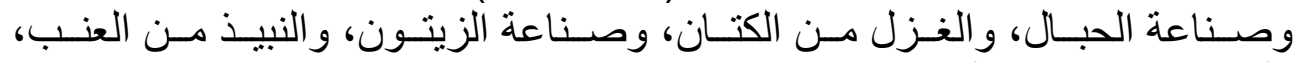

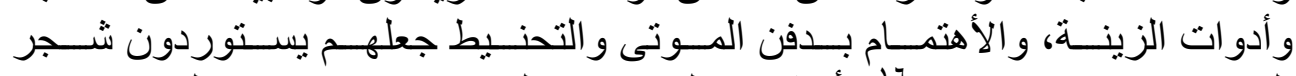

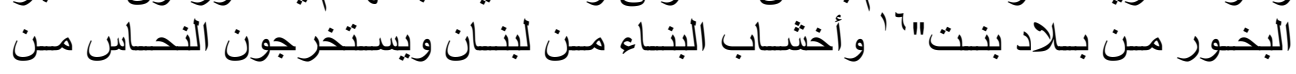
سيناء.

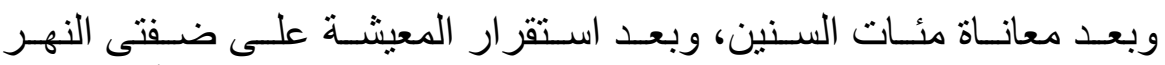

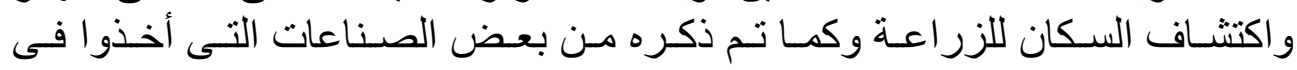

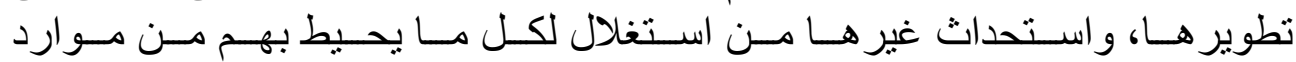

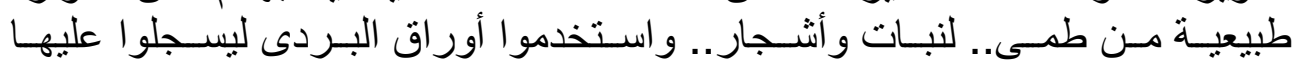

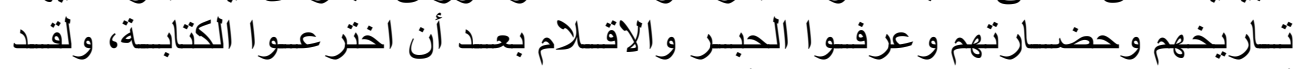

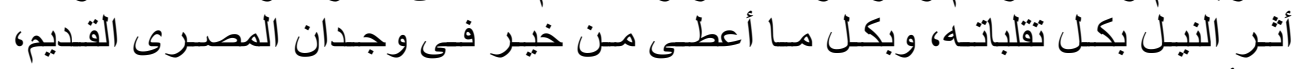

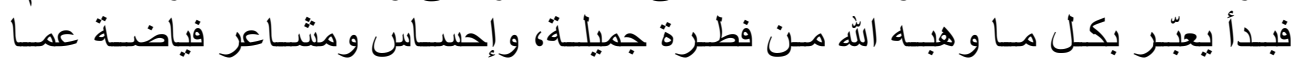

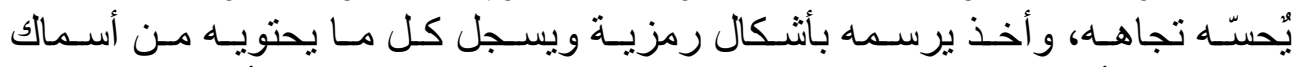

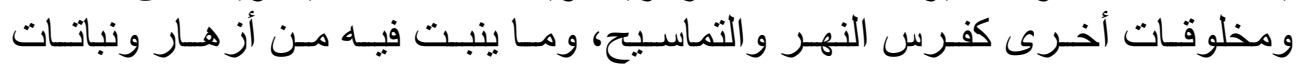

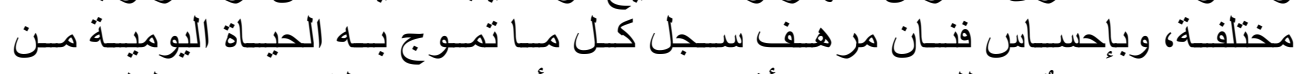

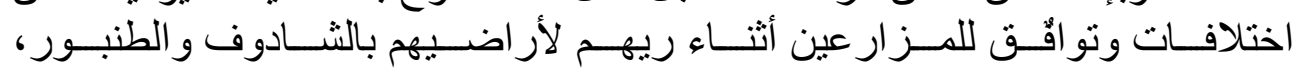

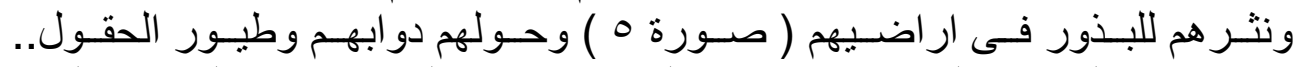

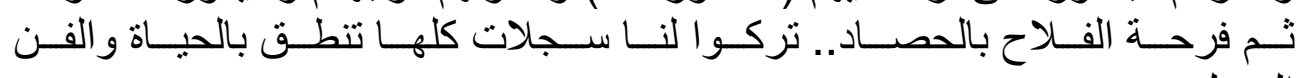

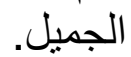

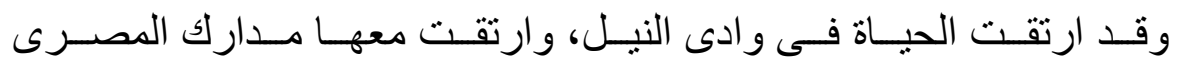

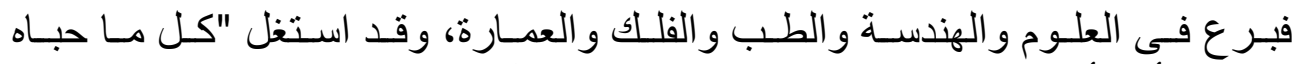

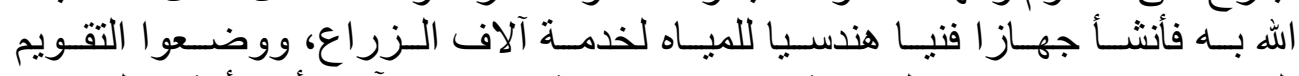

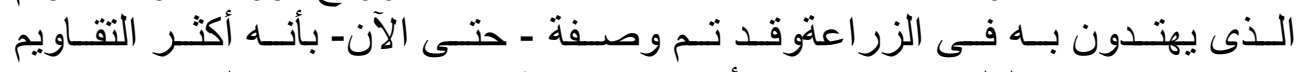

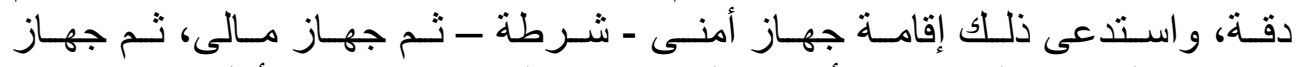

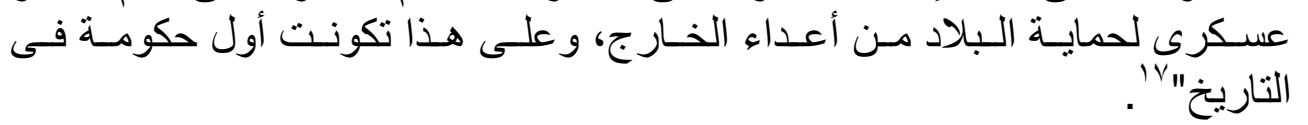

17 القاهرة

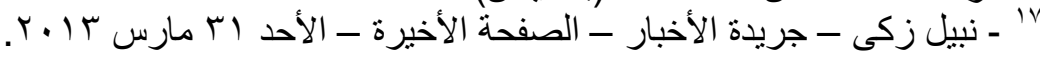




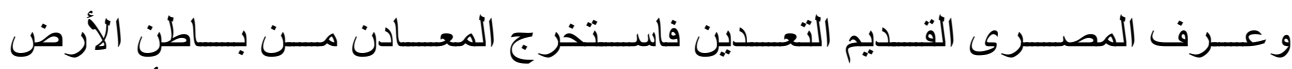

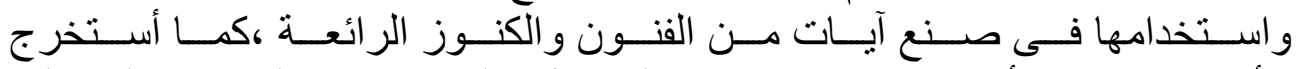

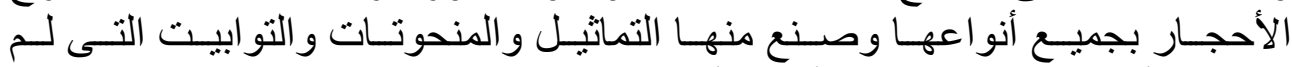

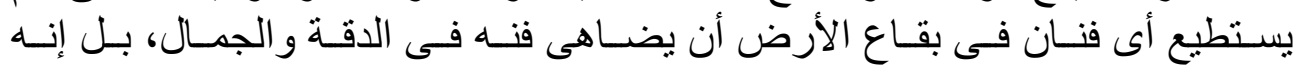

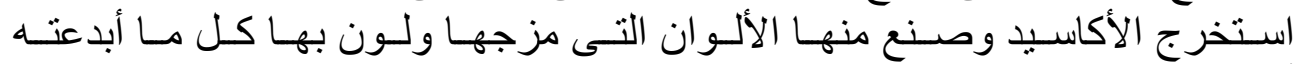

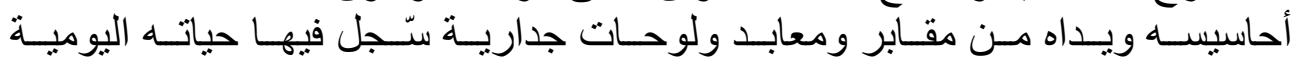

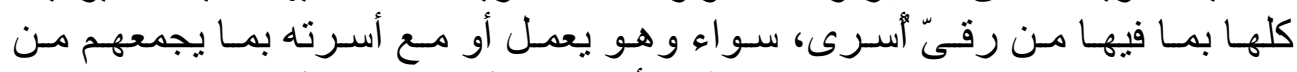

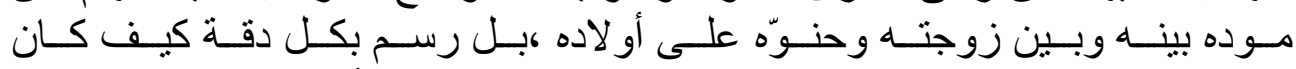

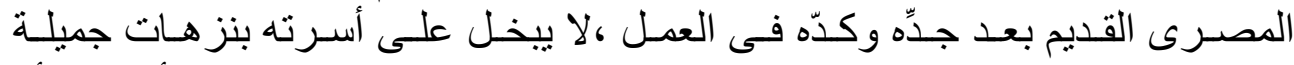

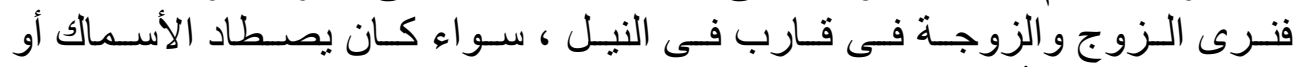

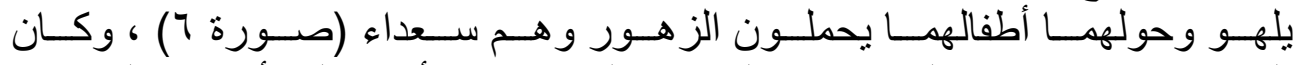

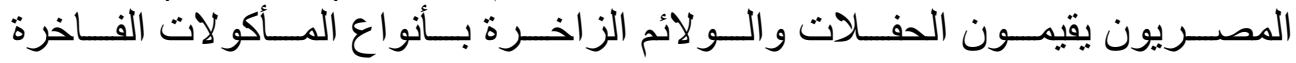

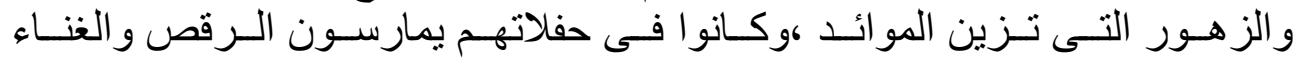

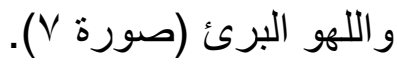

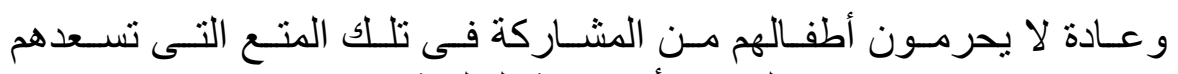
وتعلى من مداركهم.. وتنمى فيهم الحياة الأجتماعية السليمة. لأنئ.

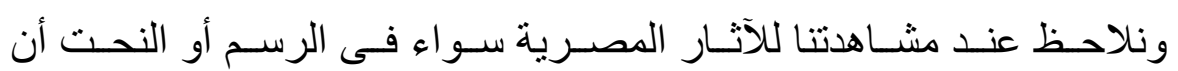

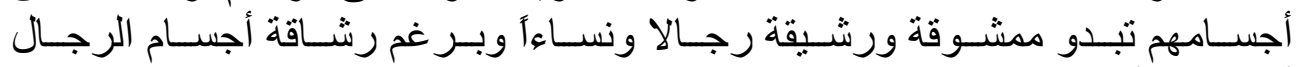

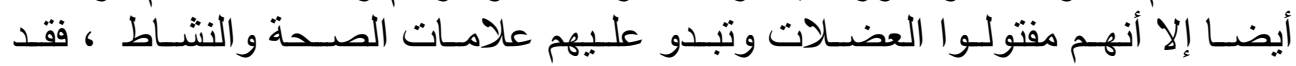

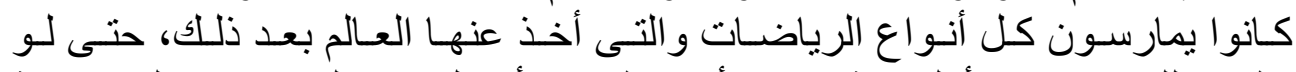

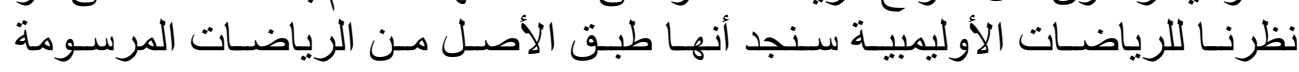

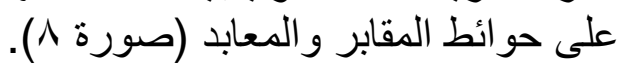

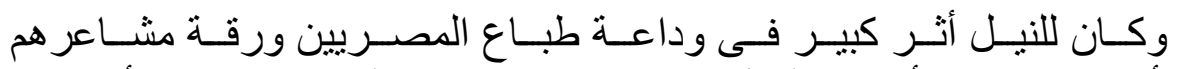

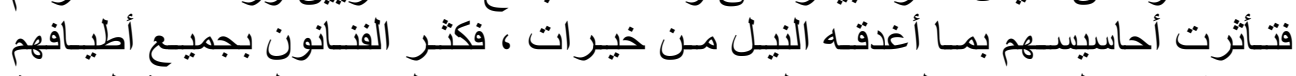

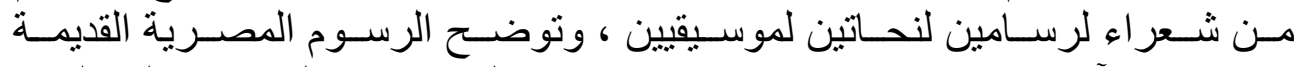

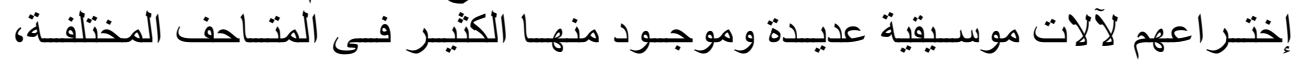

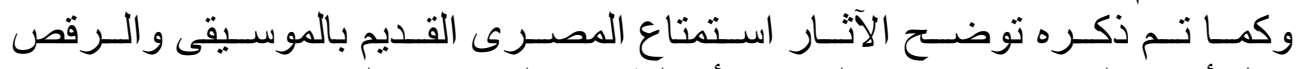
وكل أنواع الفنون، سواء في الحفلات أو الطقوس الداع الدينية فى الدعابد.

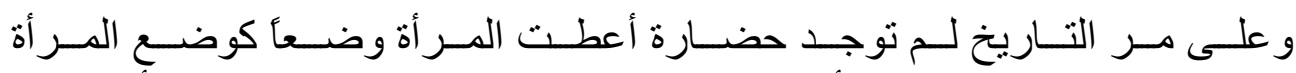

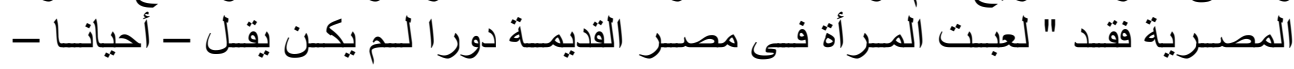

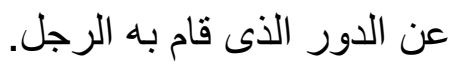

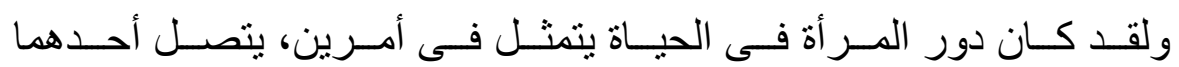

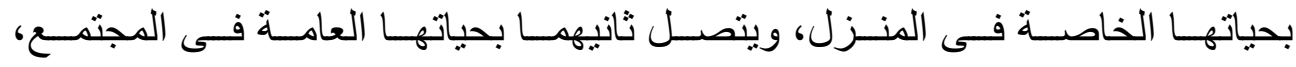




\section{دراسات في آثار الوطن العربيه 1}

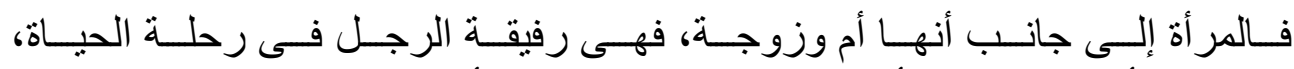

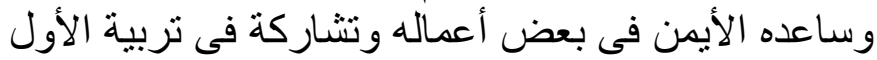

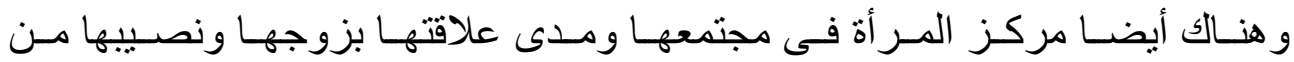

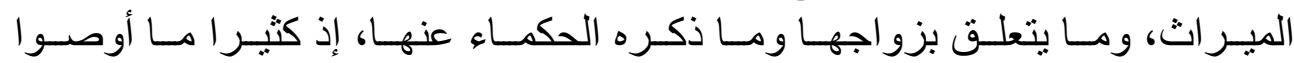

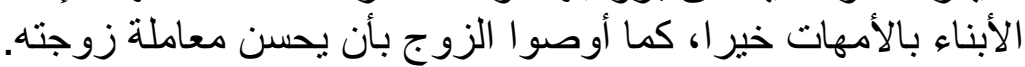

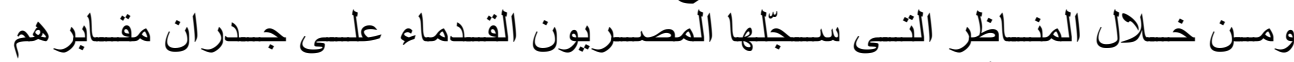

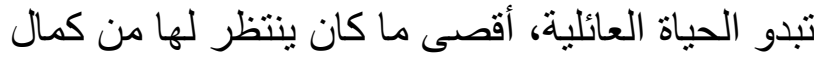

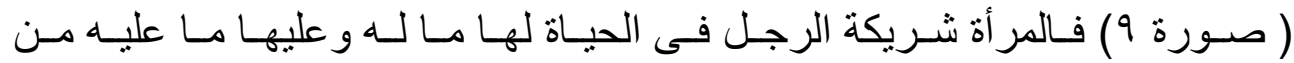

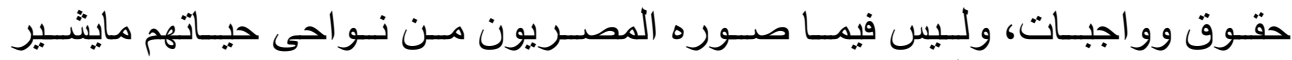

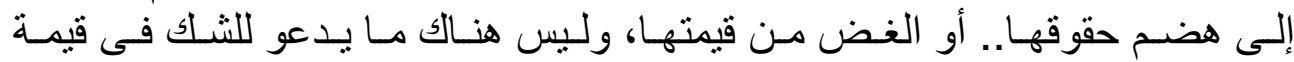

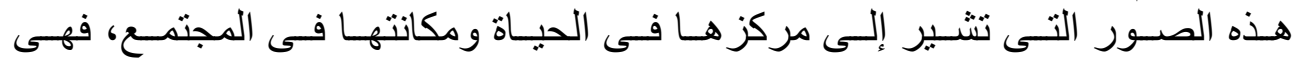

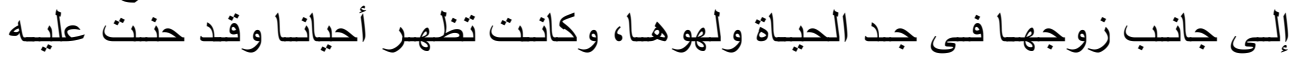

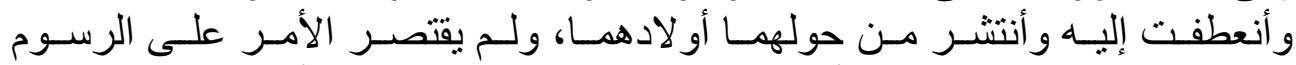

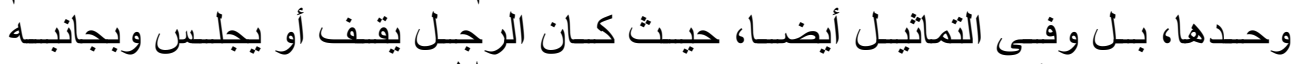

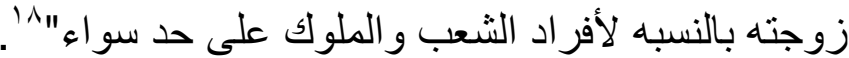

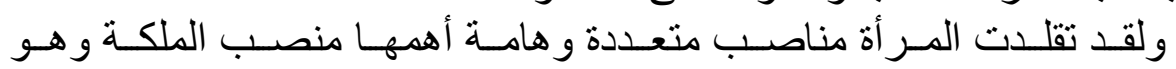

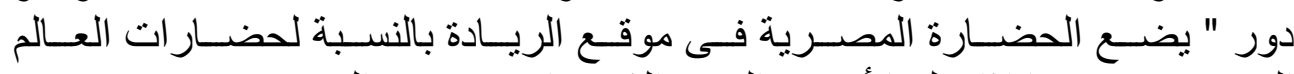

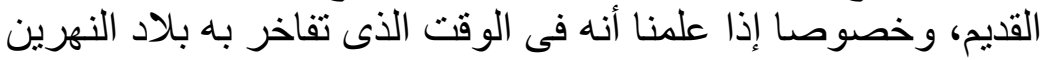

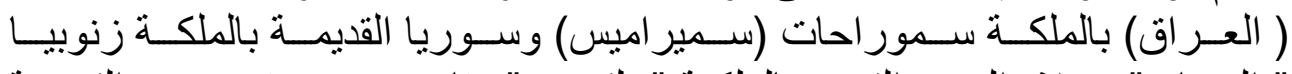

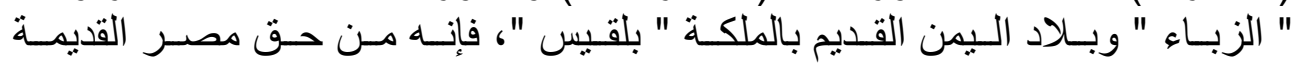

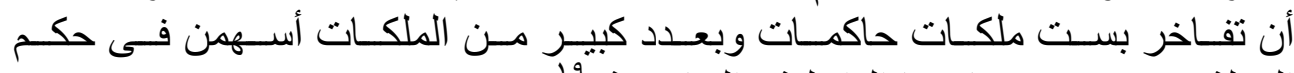

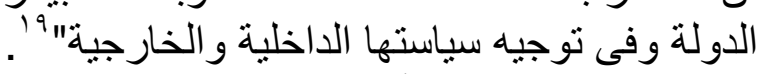

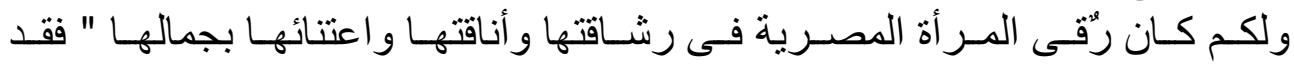

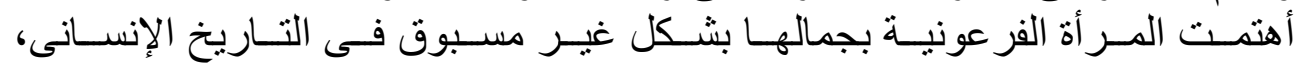

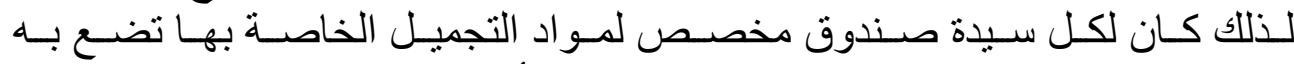

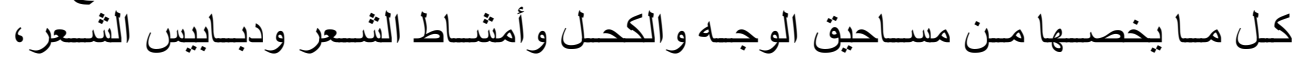

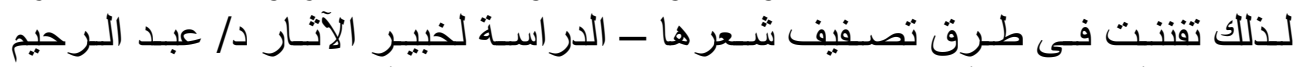

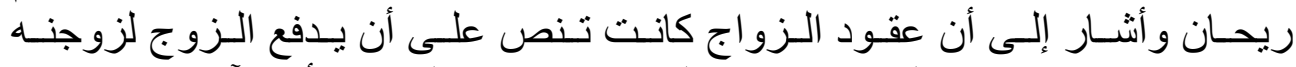

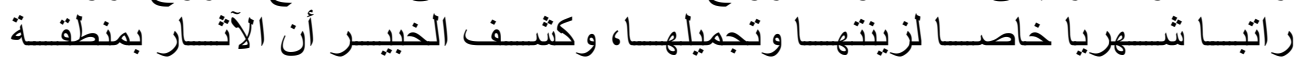

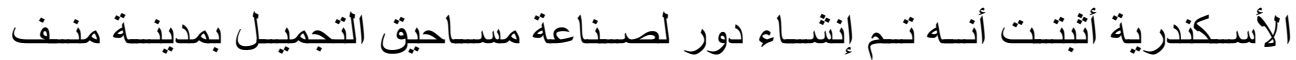

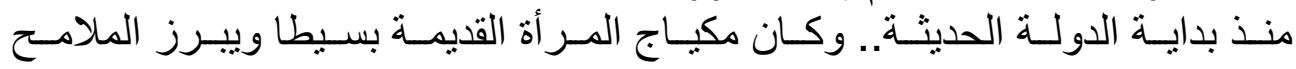

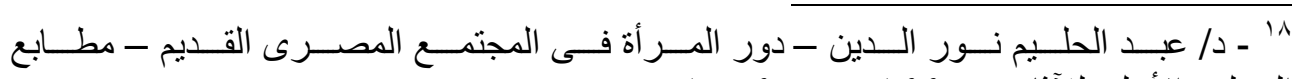

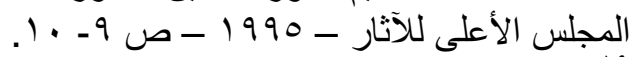

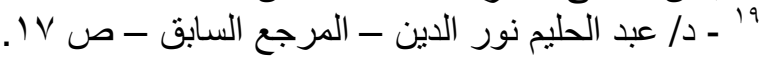




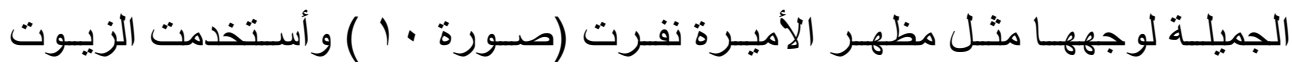

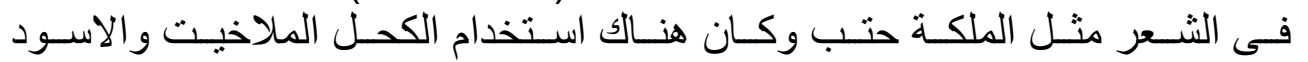

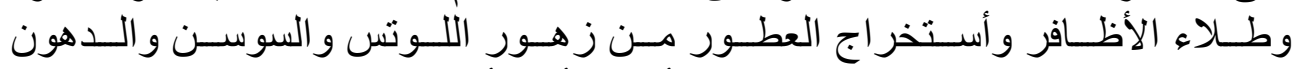

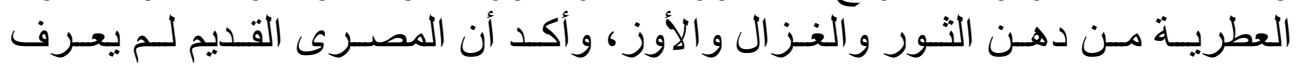

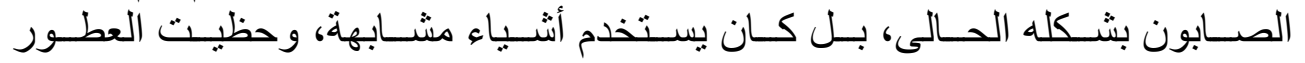

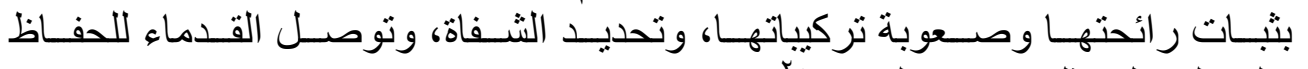

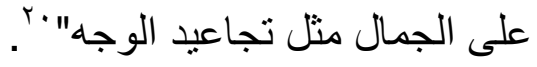

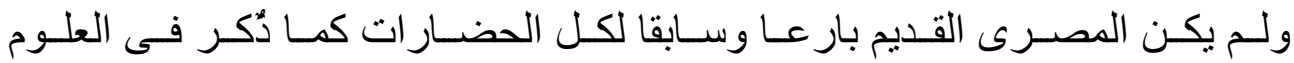

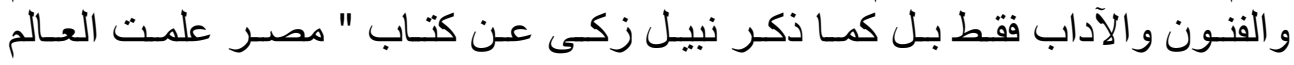

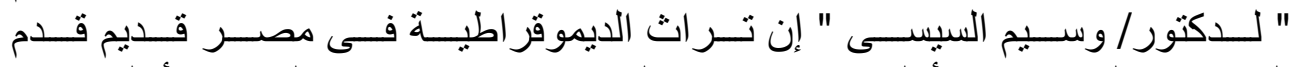

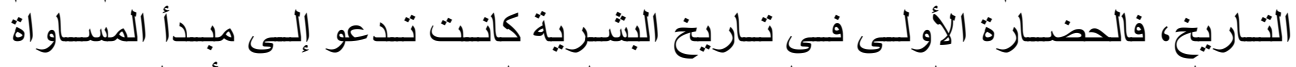

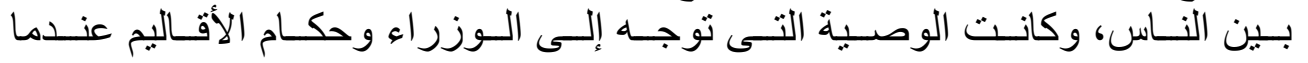

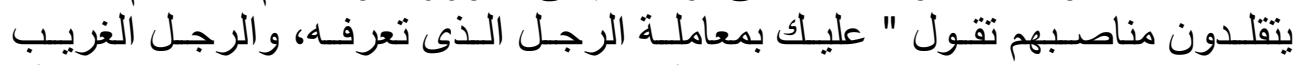

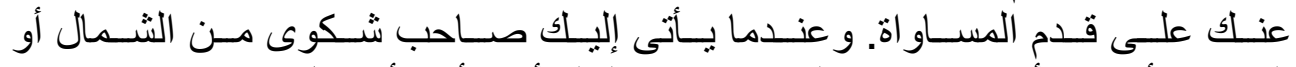

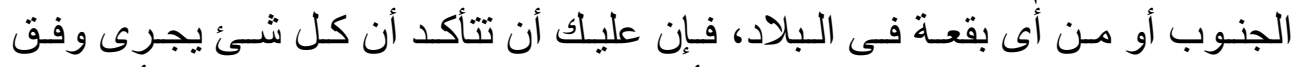

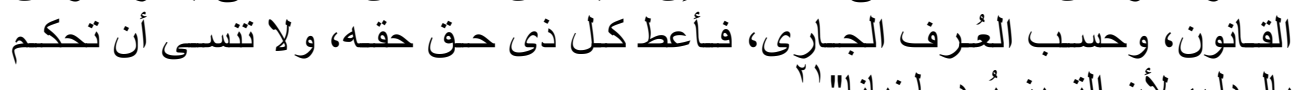

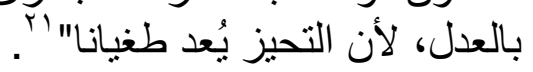

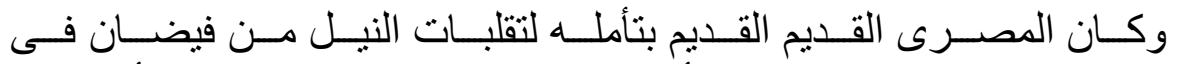

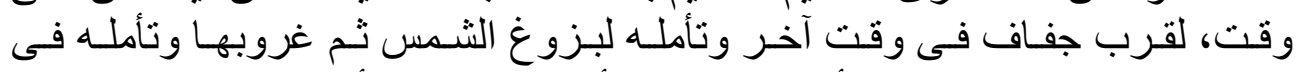

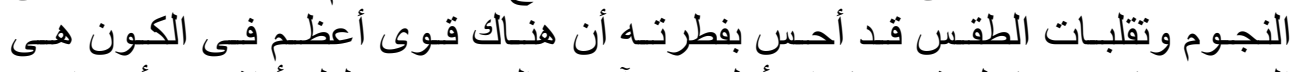

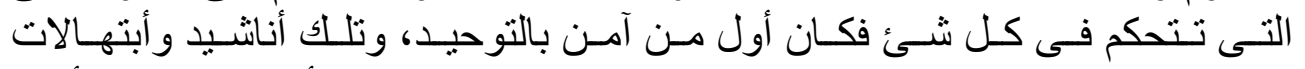

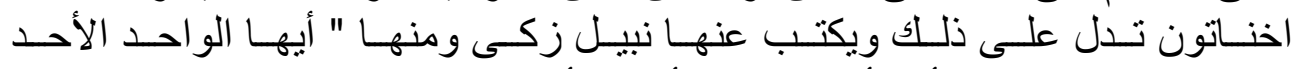

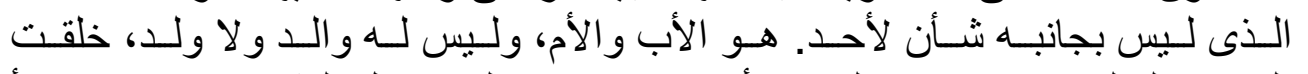

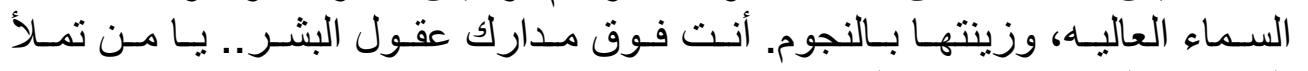

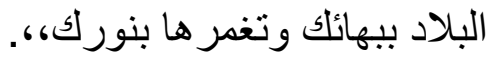

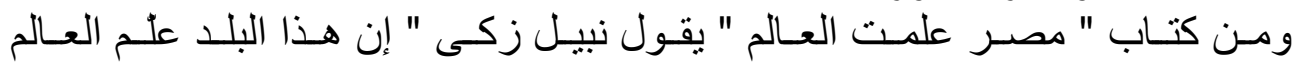

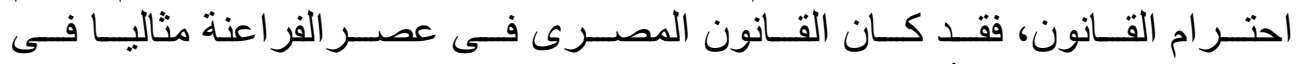

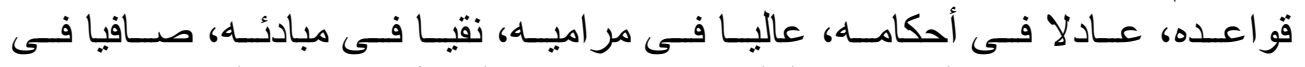

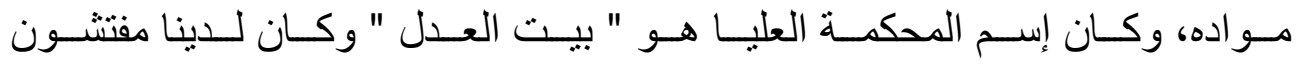

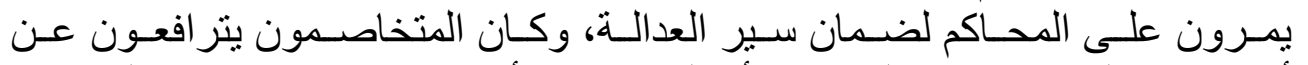

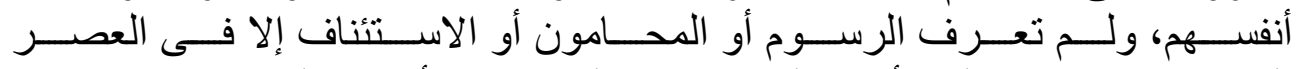

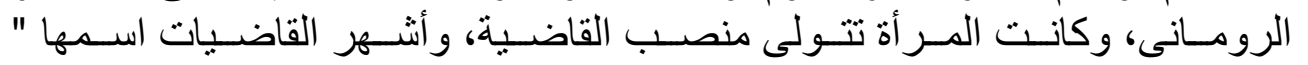

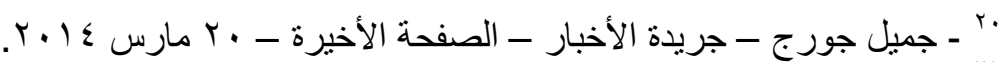

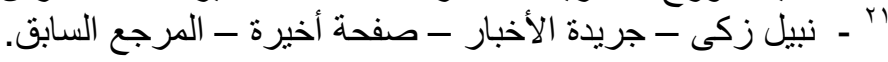

$$
\begin{aligned}
& \text { - ro7 - }
\end{aligned}
$$




\section{دراسات في آثار الوطن العربيه 1}

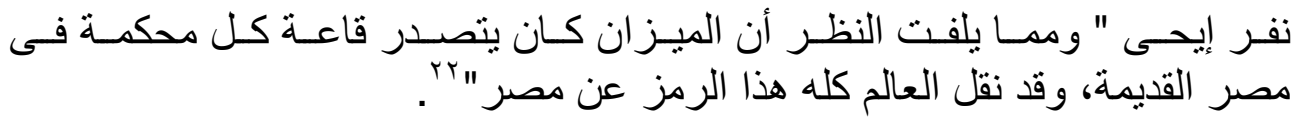

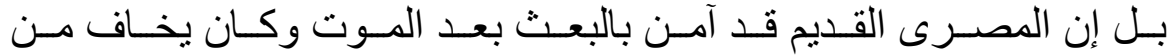

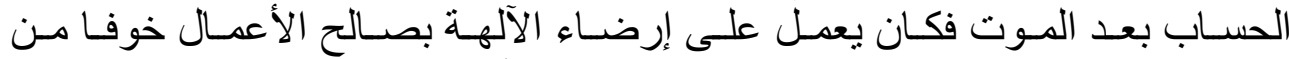

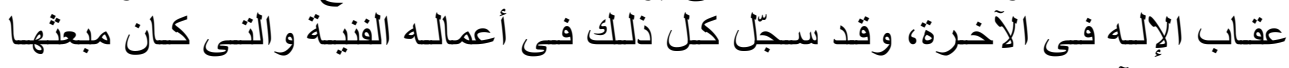

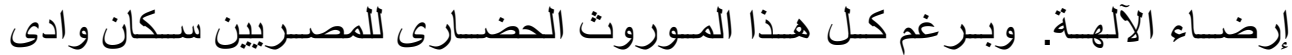

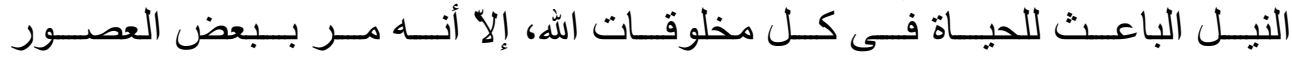

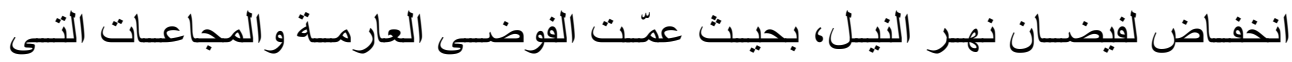

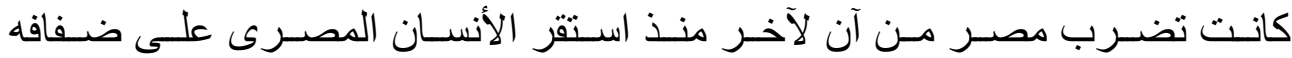
بسبب أنخفاض منسوبة، وكادت تعصف آنال بالحياة فيها.

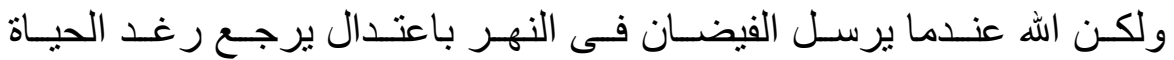

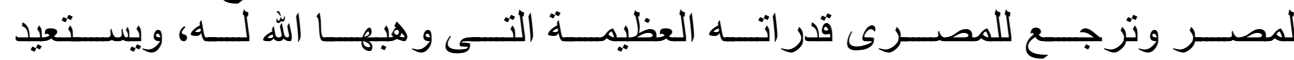

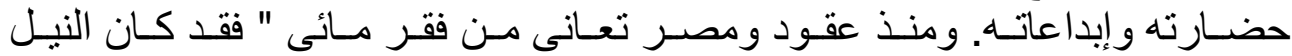

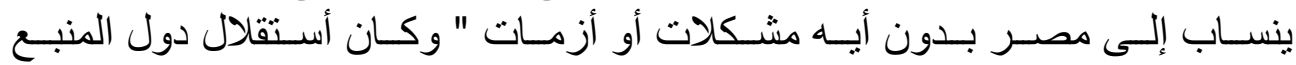

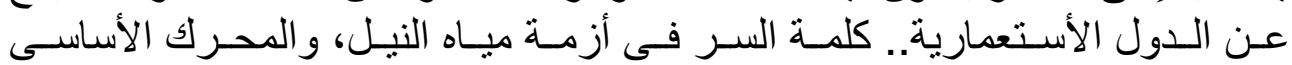

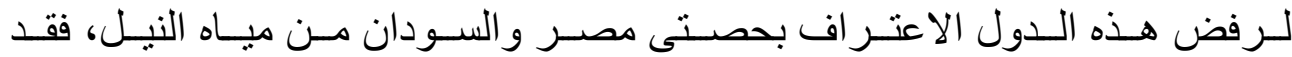

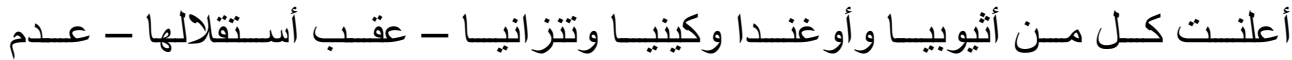

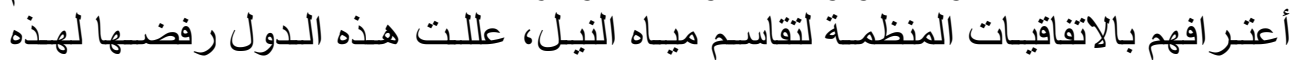

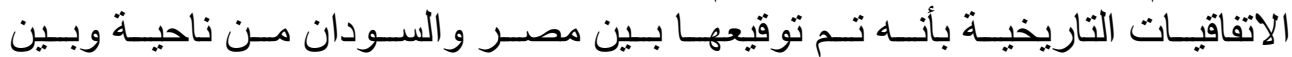

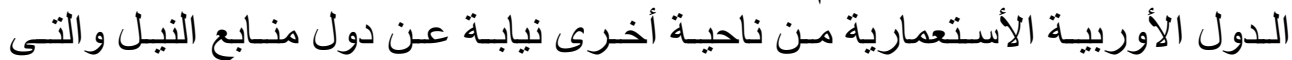

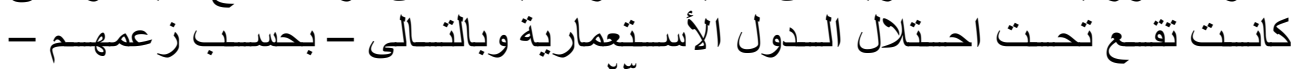

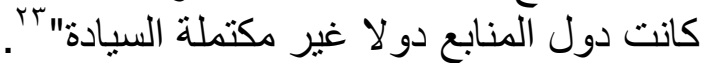

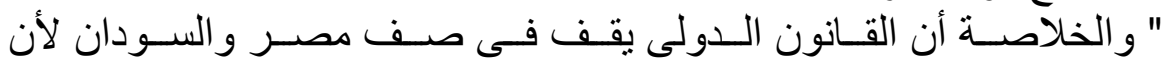

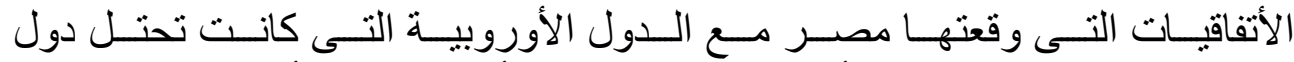

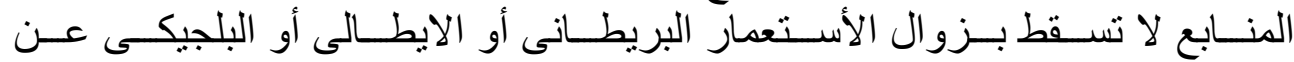

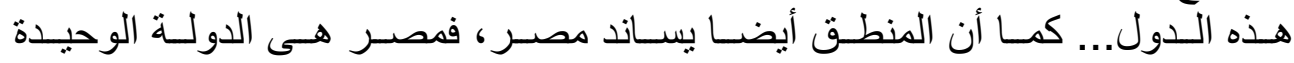

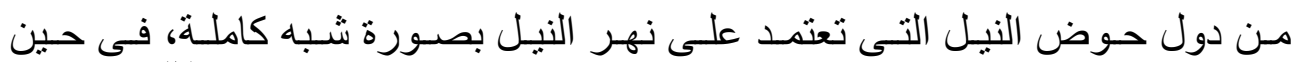

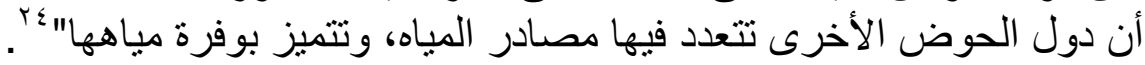

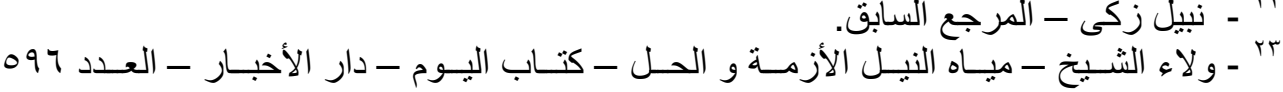

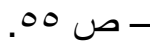

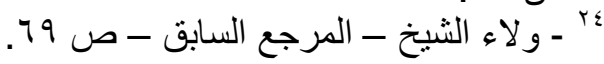




\section{دراسات في آثار الوطن العزبيمه 1}

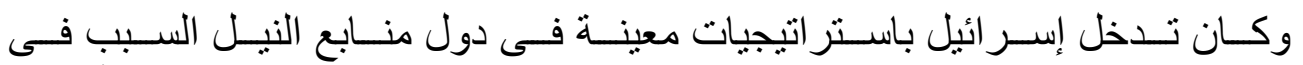

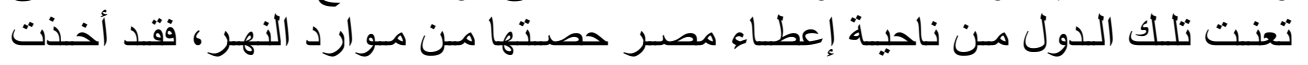

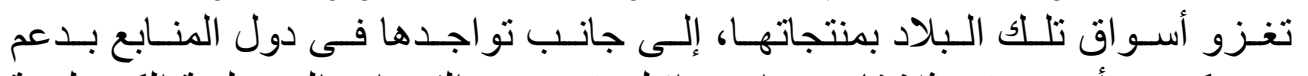

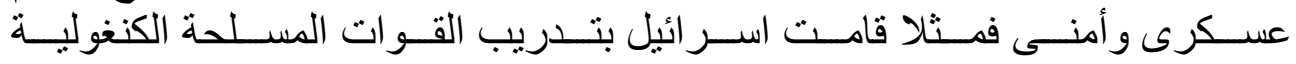
وتسليحها.

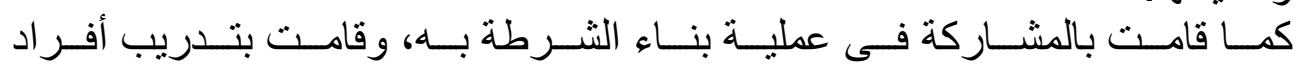

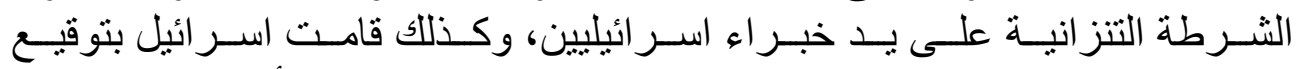

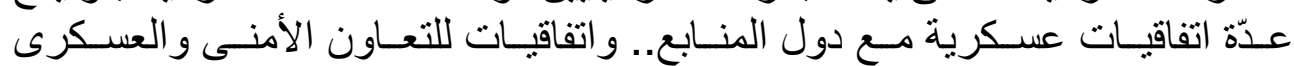

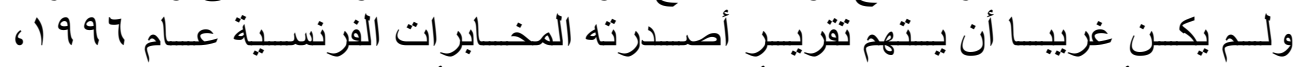

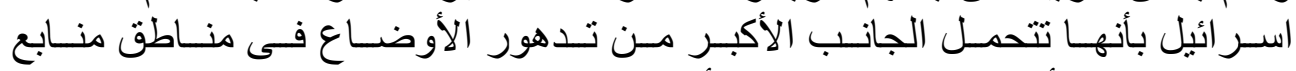

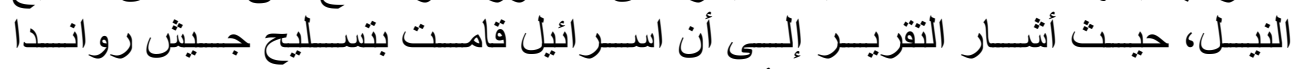

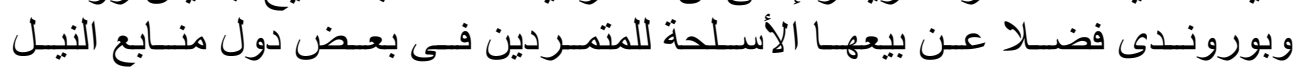

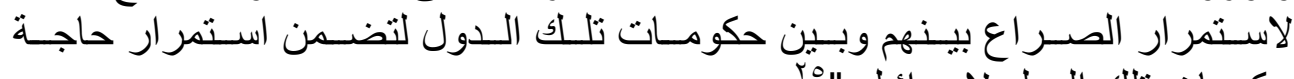

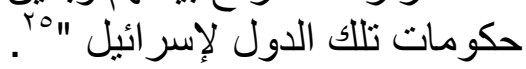

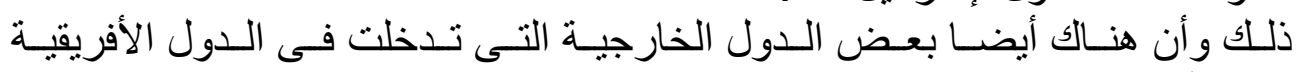

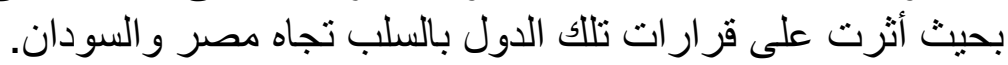

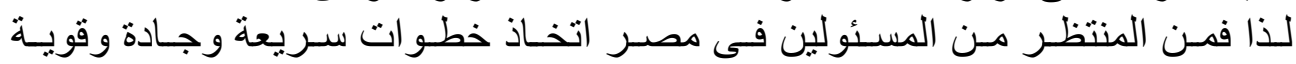

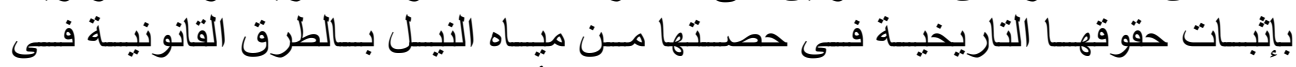

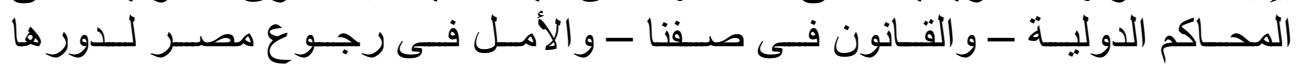

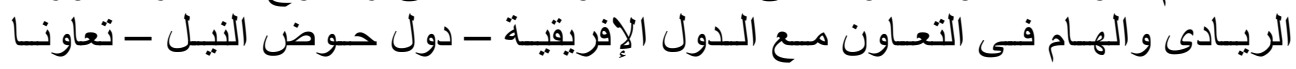

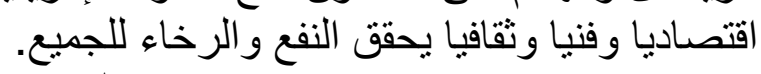

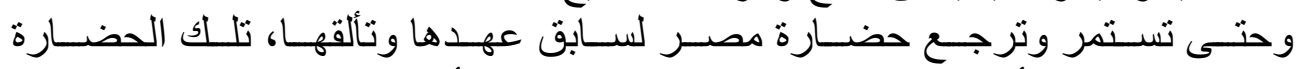

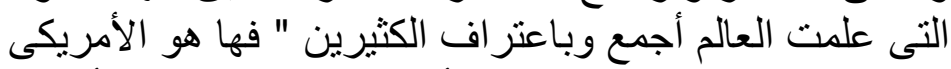

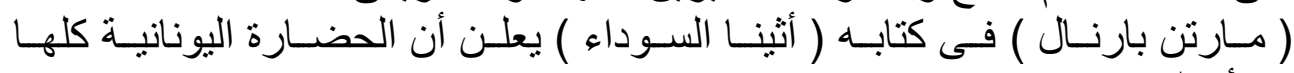

\section{ويؤكد الفيلسوف الإغريقى أفلاطون فى كتابه ( القوانين ) قائلا :

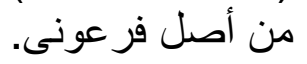

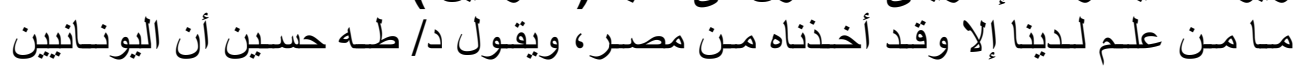

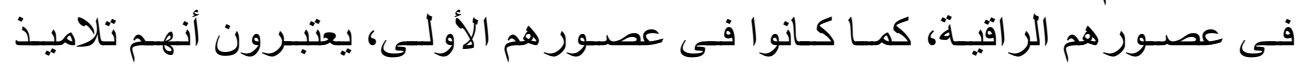

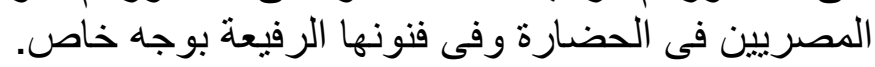

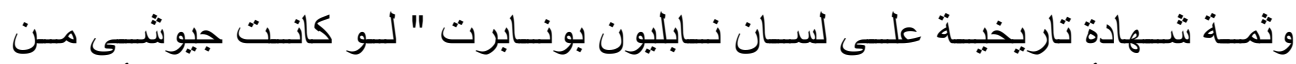

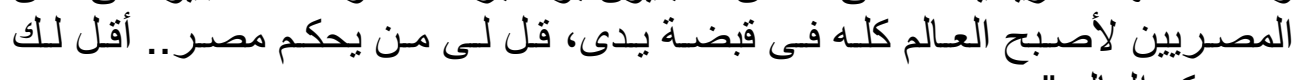

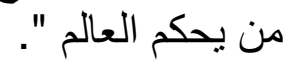

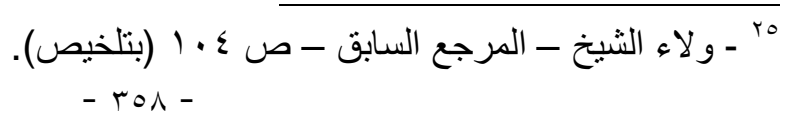




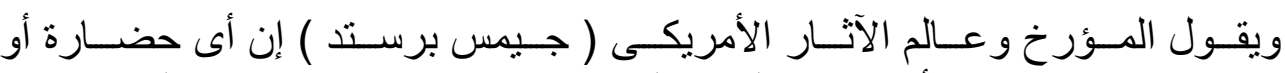

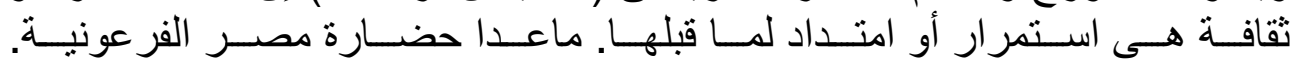

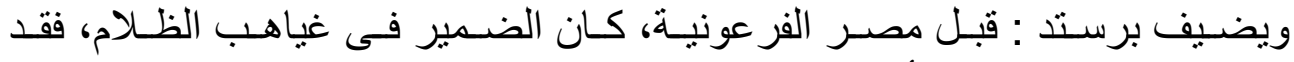

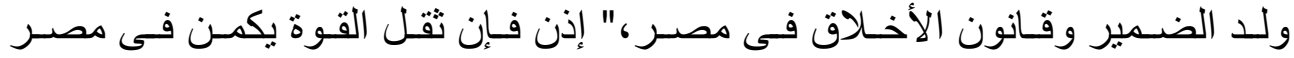

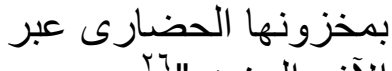

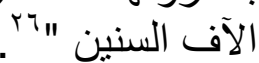


دراسات في آثار الوطن العربيه 1

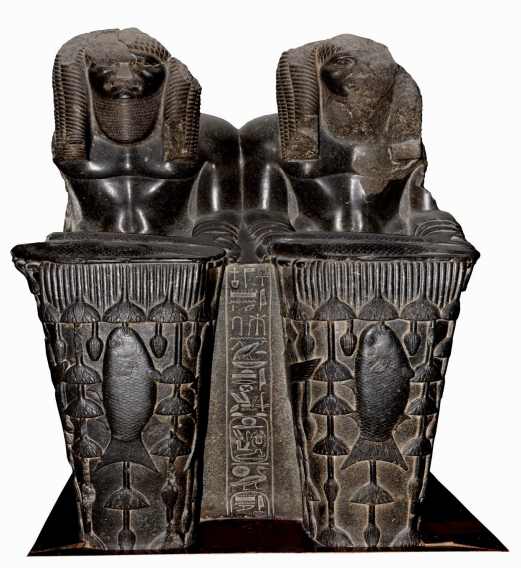

صورة رقم
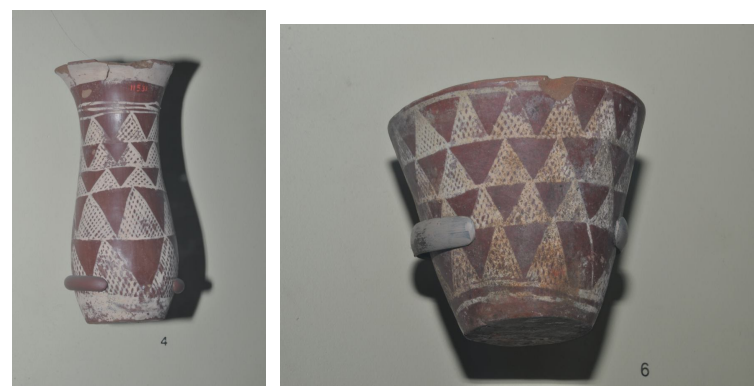

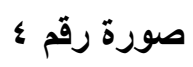
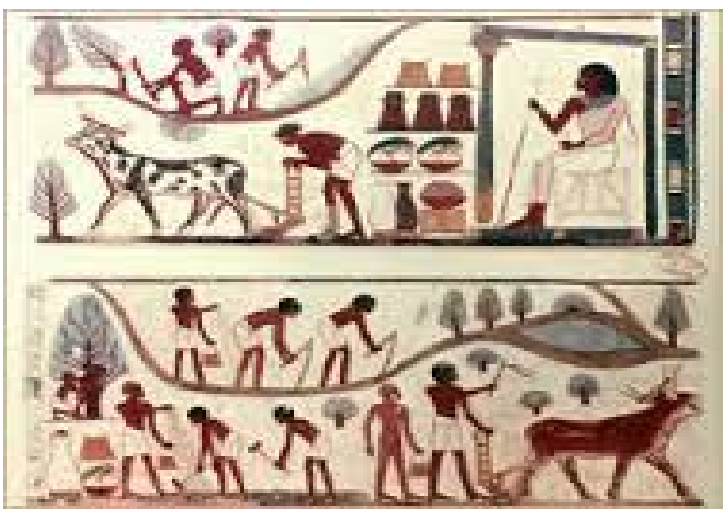

$$
\text { صورة رقم ه ب }
$$

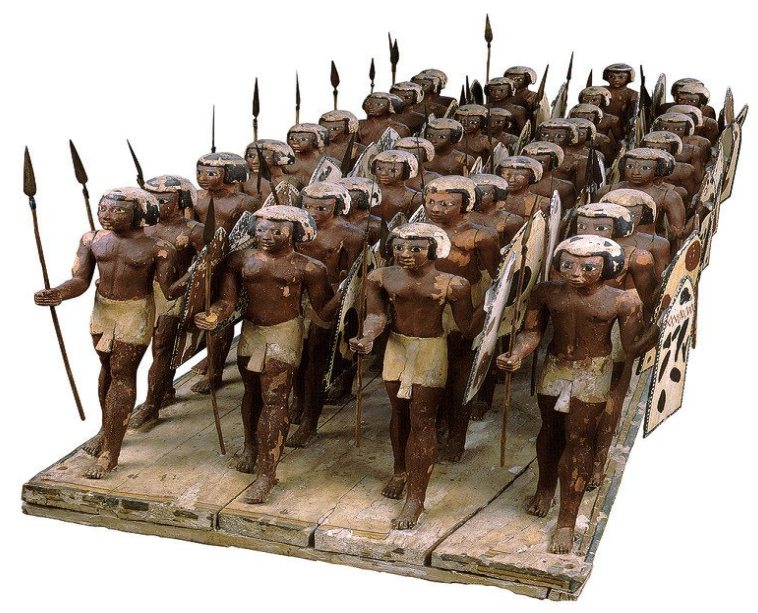

صورة رقم

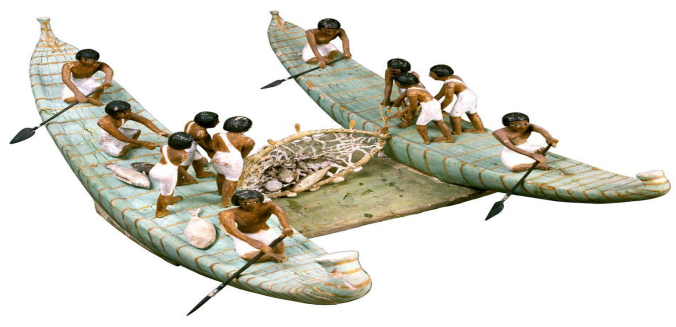

صورة رقم

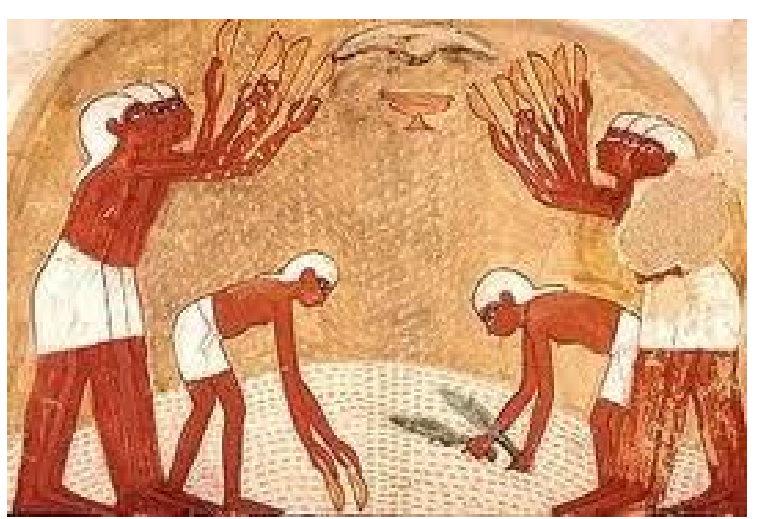

صورة رقم 
دراسات في آثار الوطن العربي 1
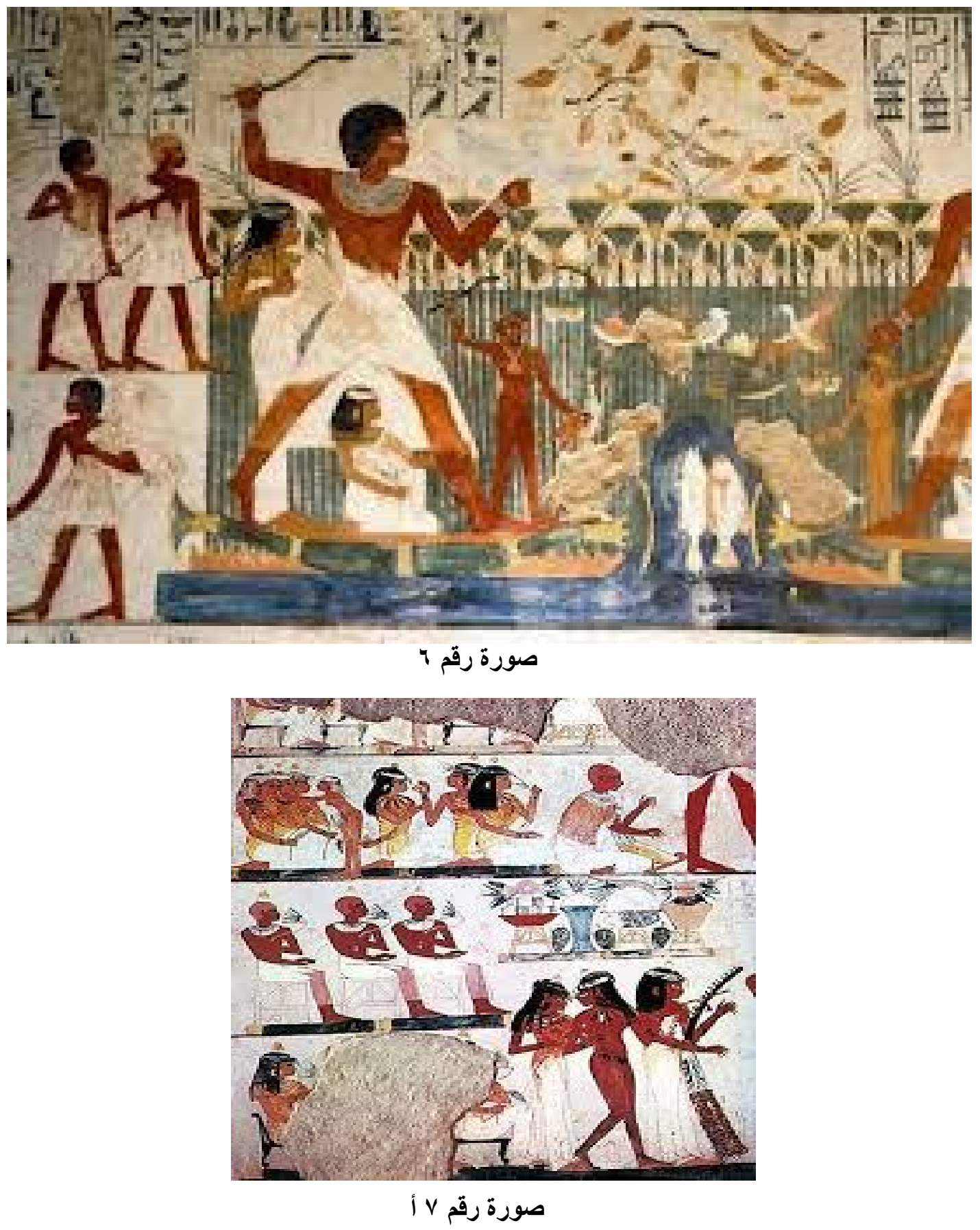
دراسات في آثار الوطن العربي 1

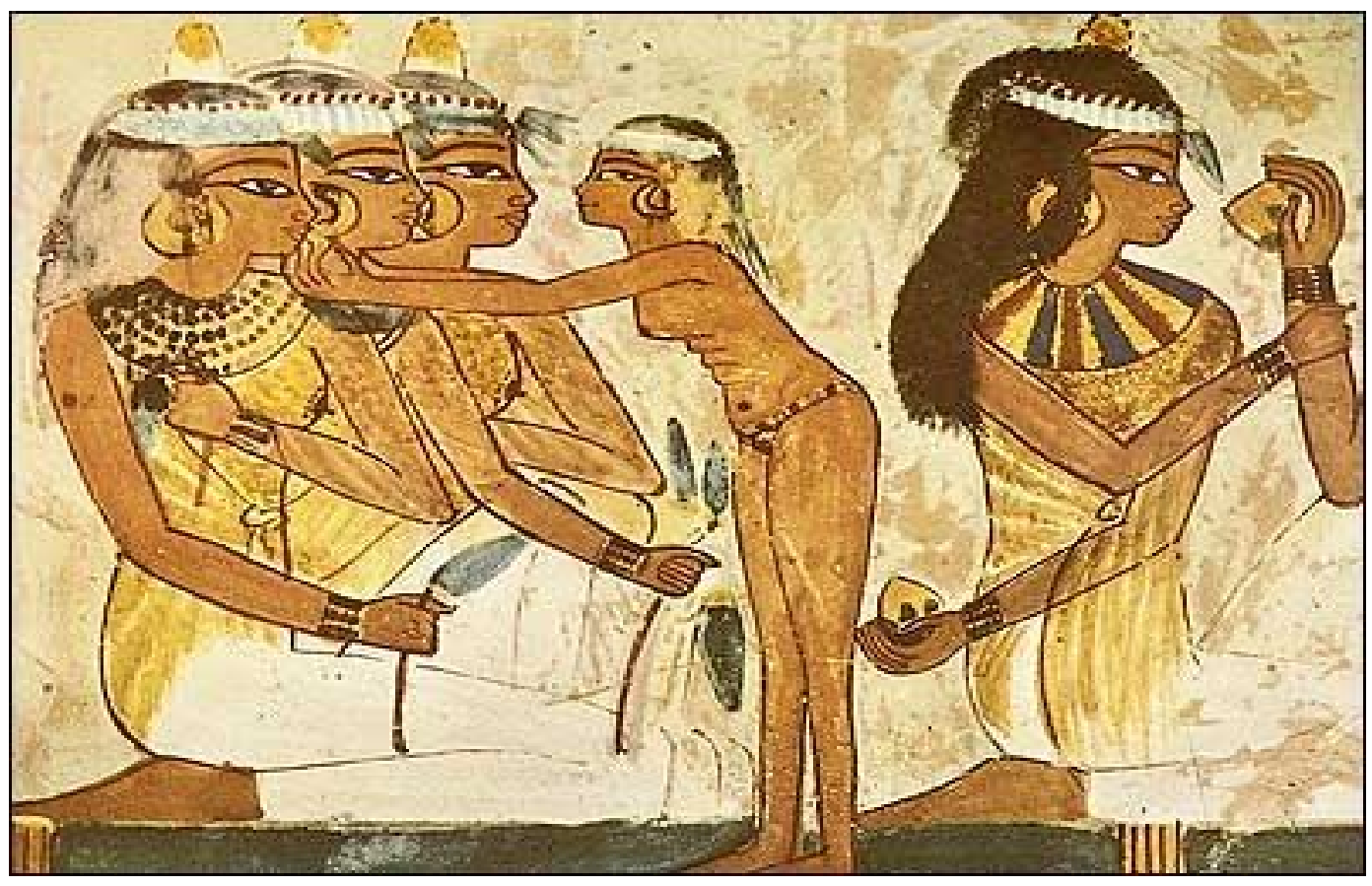

صورة رقم V ب
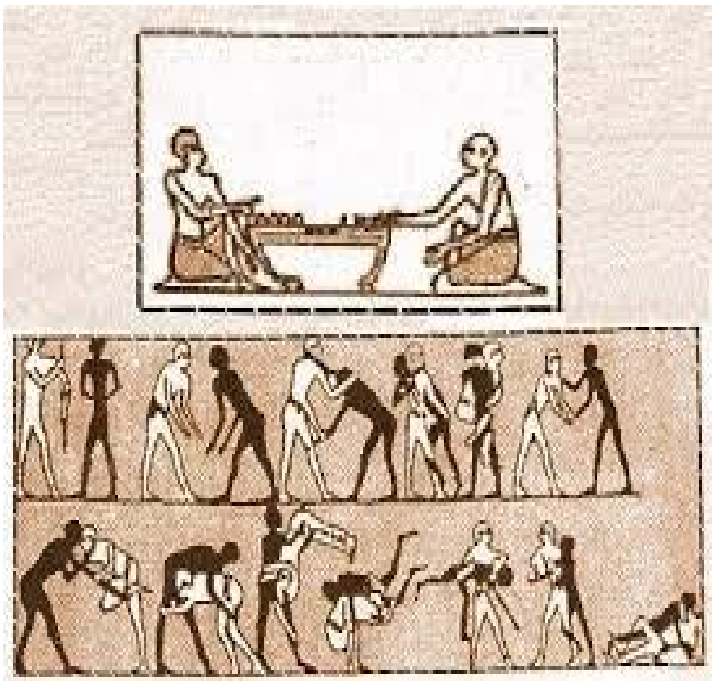

صورة رقم 1 ب

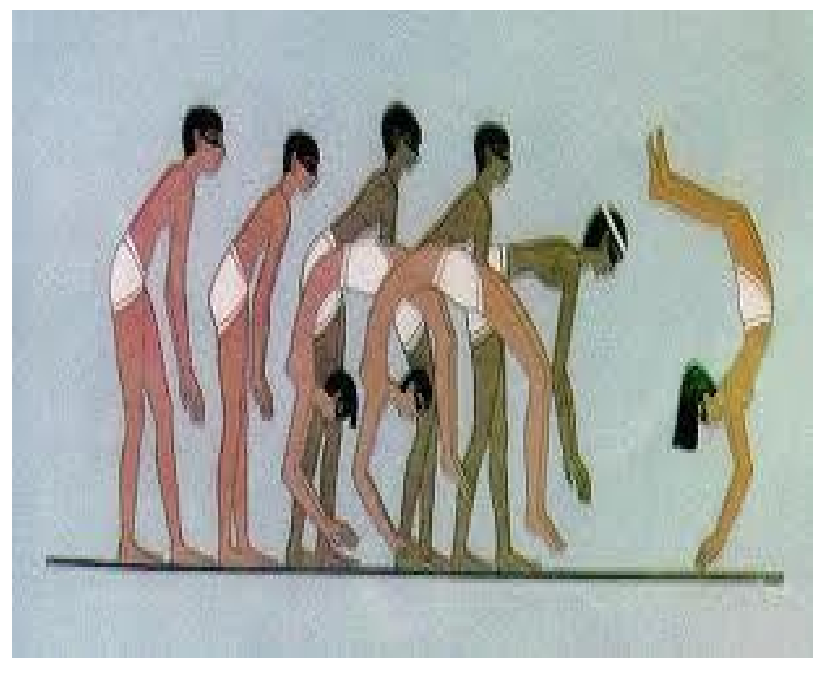

صورة رقم 1 أ

- rut - 
دراسات في آثار الوطن العربيه 1
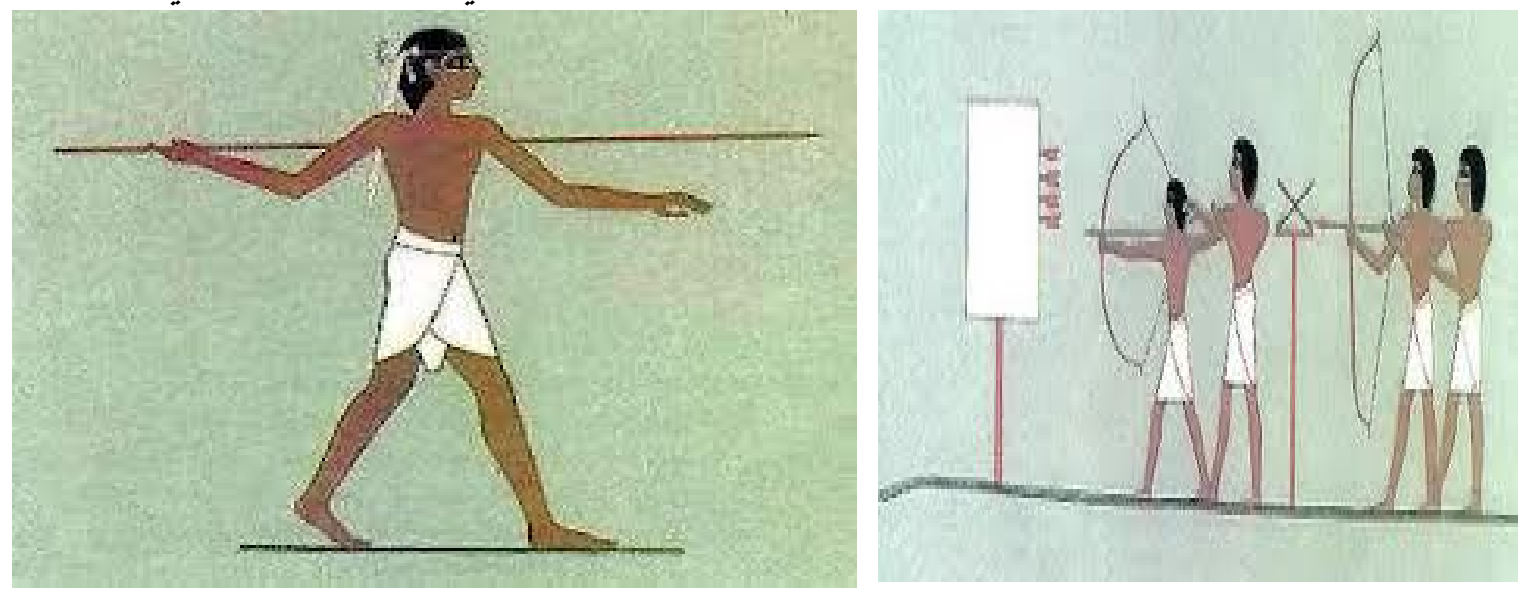

\section{صورة رقم 1 د}

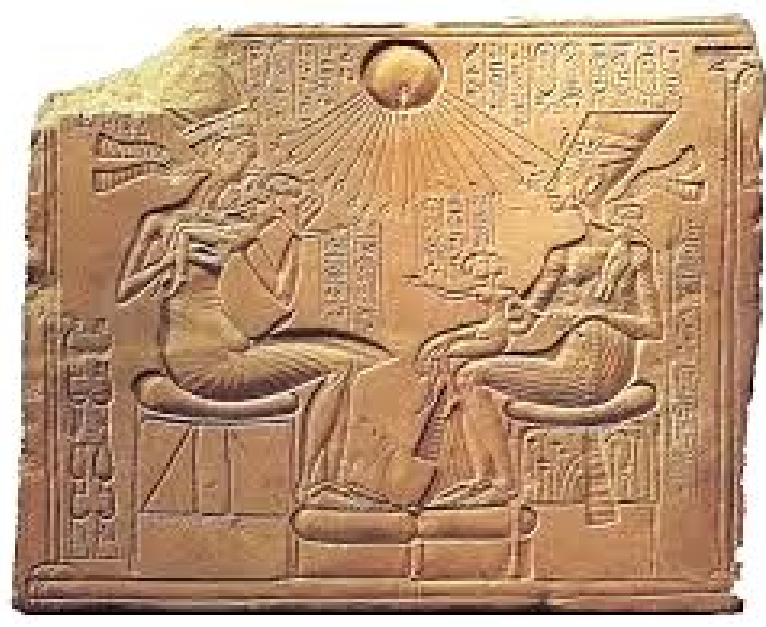

صورة رقم 9 ب

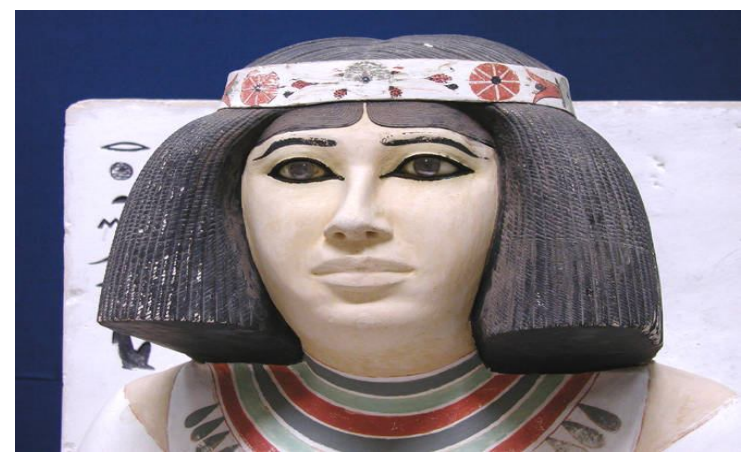

صورة رقم · 1 ب
صورة رقم ^ ج

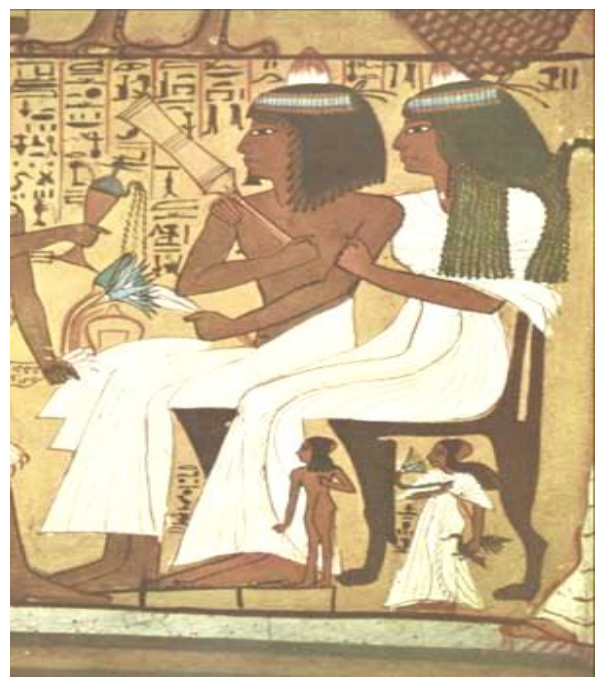

صورة رقم 9 أ

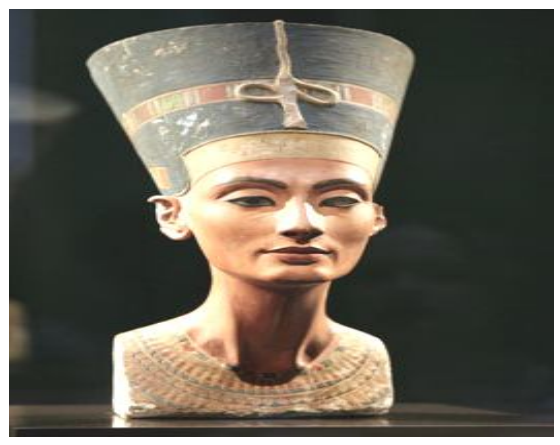

صورة رقم . 1 أ 